\title{
Marcos interpretativos de lo social en la vivencia de la «nueva pobreza»
}

\author{
Araceli SERRANO PASCUAL \\ Facultad de Ciencias Políticas y Sociología. Departamento de Sociología IV \\ Universidad Complutense de Madrid \\ araceli@cps.ucm.es
}

Daniel PARAJUÁ NAVARRETE

Facultad de Ciencias Políticas y Sociología. Departamento de Antropología Social.

Universidad Complutense de Madrid

dparajua@pdi.ucm.es

Ángel ZURDO ALAGUERO

Facultad de Ciencias de la Información. Departamento de Sociología VI

Universidad Complutense de Madrid

angel.zurdo@ccinf.ucm.es

Recibido: 17-01-2013

Aceptado: 21-03-2013

\begin{abstract}
RESUMEN
A través de un análisis de material empírico cualitativo, en este artículo se analiza cómo los llamados «nuevos pobres» construyen sus marcos interpretativos vinculados a diferentes aspectos relacionados con la organización social, la desigualdad, los procesos de polarización social, el empobrecimiento, así como sobre su capacidad de agencia política. Se ha podido comprobar cómo se está produciendo un ambivalente y matizado proceso de resquebrajamiento del parapeto mítico sobre el que se ha asentado buena parte del desarrollo del modelo capitalista (mito del progreso, de la meritocracia, de la sociedad de clases medias o del consumo como vía de integración social). Paralelamente se consideran los nuevos marcos interpretativos legitimadores del modelo emergente, asentados en la auto-responsabilización, la culpabilización, la fragmentación del colectivo y la necesidad de ocultamiento de la situación de pobreza y malestar.
\end{abstract}

Palabras clave: marcos interpretativos, «nueva pobreza», procesos de re-significación

\section{Interpretative frameworks of the social in the living of the «new poverty»}

\begin{abstract}
By mean of qualitative empirical evidence, this article analyzes how the so called «new poor» constructs interpretive frameworks that are linked to different aspects related to social organization, inequality, the process of social polarization, impoverishment, as well as their capacity for political agency. The evidence illustrates the production of an ambivalent and nuanced process of breaking myths on which important aspects of the development of the capitalist model is established (myths of progress, meritocracy, middleclass society, or the consumption as a way of social integration). In addition, new interpretive frameworks are evaluated supporting the emerging model established in self-responsibility, guilt, fragmentation of the collective poor, and their want to conceal their own poverty.
\end{abstract}

Keywords: interpretative frameworks, «new poverty», re-signification processes 


\section{REFERENCIA NORMALIZADA}

Serrano, A., Parajuá, D. y Zurdo, Á. (2013). Marcos interpretativos de lo social en la vivencia de la «nueva pobreza.» Cuadernos de Relaciones Laborales. Vol. 31, núm. 2, p. 337-382.

SUMARIO: Introducción. 1. Antecedentes en el estudio de los procesos de subjetivación y la conformación de marcos interpretativos de lo social vinculados a la vivencia de la pobreza. 2. Objetivos y metodología. 3 . Marcos interpretativos de lo social en el caso de los «nuevos pobres». 3.1. Debilitamiento del entramado mítico del modelo capitalista. 3.2. La responsabilización individual culpabilizadora: el pecado del consumo como re-edición del pecado original. 3.3. La política de las apariencias y la autocensura del malestar. 4. Concluyendo. 5. Anexo: ficha técnica de la investigación. 6. Bibliografía.

\section{Introducción}

La eclosión de la crisis económica - y su prolongación en el tiempo-, no solo ha mostrado un efecto social demoledor entre los sectores sociales más 'precarizados', produciéndose un intenso proceso en curso de polarización social y de empobrecimiento generalizado en la sociedad española ${ }^{1}$, sino que también ha introducido de manera paralela un poderoso vector de re-elaboración y transformación de las representaciones sociales circulantes, así como de los marcos interpretativos con respecto a múltiples esferas de lo social.

Es este un momento cualitativamente diferente, a pesar de ser una más entre las crisis del capitalismo tardío, que está produciendo un incremento descomunal de las fracturas sociales, de la fragmentación y la polarización social y de los procesos de empobrecimiento, multiplicándose los grupos más vulnerables, más fragilizados, más pobres. Uno de los efectos más remarcables de estas transformaciones se relaciona con la creciente heterogeneización de la pobreza, y, también, con el desarrollo de una situación en la cual la ausencia de posibilidades de participación en el mercado de trabajo, o la obligación de hacerlo en condiciones de precariedad y subempleo, se extiende a sectores más amplios de la población. No es este el espacio para referirnos a cómo estos procesos se concretan en cifras que visibilizan dichas transformaciones. Baste, en este contexto, entresacar unos pocos indicios a nivel nacional. Según los datos de la Encuesta de Condiciones de vida (ECV) del INE para $2012^{2}$ la tasa de pobreza alcanzó el $21,1 \%$ de la población española, el

${ }^{1}$ Belzunegui (2012) utiliza el concepto socialización de la pobreza para referirse a una realidad social caracterizada por sus mayores cotas de vulnerabilidad, que afecta en la actualidad a capas de población cada vez más amplias, y a sectores que hasta el momento habían permanecido protegidos frente a sus riesgos.

${ }^{2}$ Estos datos para 2012 son todavía provisionales, quedando todavía pendientes de su explotación definitiva para el presente año en curso. Todas estas cifras en las que interviene de manera fundamental el umbral de pobreza son especialmente preocupantes, ya que el umbral que define la pobreza relativa se ha reducido en el periodo 2009-2011 un 6\%, situándose en torno a los $7.500 €$ anuales por ciudadano para este último año (Aragón y otros, 2012). Es decir, se ha producido un empobrecimiento generalizado de la población, lo 
indicador de riesgo de pobreza y exclusión social (AROPE) el $26,8 \%{ }^{3}$ y el volumen de hogares con dificultades para llegar al final de mes se elevó al 31,8\%. Algunos otros datos indicativos de situaciones de privación y vulnerabilidad son los siguientes: la tasa de hogares con todos los miembros en paro se situó en el $10,1 \%$ en $2012^{4}$; el porcentaje de trabajadores pobres alcanzó el 12\% de la población ocupada (Aragón y otros, 2012); la tasa de no cobertura de las prestaciones por desempleo (contributivas o asistenciales) se sitúa en un $34,3 \%$ para $2012^{5}$, el volumen de población que se puede considerar como plenamente integrado desciende desde el $47,5 \%$ en 2007 hasta el 37,2\% en 2011, según los datos proporcionados por López Jiménez y Renes $^{6}$, y por último, el número de personas atendidas por Cáritas ha pasado de 370.251 personas en 2007 a 1.015.276 personas en 2011 (Equipo de estudios de Cáritas, 2012).

Todas estas pinceladas nos proporcionan una imagen 'impresionista' de las dimensiones del fenómeno que se aborda. Para una consideración exhaustiva de estas estadísticas se puede consultar: Embid (2013), FOESSA (2013), Laparra y Pérez Eransus (2010 y 2012), Salido (2012), Colectivo Ioé (2012), EAPN (2012), INE (ECV, 2012 y EPA, 2012), Belzunegui (2012), Viçens (2012), Intermón-Oxfam (2012) o López Jiménez y Renes (2011).

Este proceso de empobrecimiento, que se desarrolla en un contexto de contracción y recortes de los servicios públicos en general, y de los de garantía de rentas en particular (que han afectado de manera fundamental a los sectores más vulnerables $)^{7}$, ha venido acompañado de una crucial transformación de las formaciones ideológicas, de las cosmovisiones y miradas sobre el mundo social, así como de las formas de su reproducción. En este sentido, podríamos hablar de un momento de profundización (extremadamente ambivalente) en los problemas de legitimación del

que provoca la bajada de los umbrales puesto que estos se calculan en relación a la mediana de la población, de manera que una parte de los hogares considerados en situación de pobreza en 2009 no lo son en 2012.

${ }^{3}$ Según el Informe $n^{\circ} 32$ de Intermón-Oxfam (2012) siguiendo este indicador, se calcula que alrededor de 12,7 millones de personas en España están en situación de riesgo de pobreza y exclusión social, lo que supone un aumento en 2,1 millones de personas desde 2008.

${ }^{4}$ Según datos de la EPA (II trimestre 2012).

${ }^{5}$ Datos ofrecidos por el Barómetro Social de España (Colectivo Ioé, 2012: 4).

${ }^{6}$ Estos datos se calculan a partir de las Encuestas FOESSA (2007/2009) especialmente diseñadas para medir el alcance de la exclusión social, para lo cual se construye un índice multidimensional y complejo a partir de treinta y cinco indicadores. Según estos datos, en 2009 encontraríamos un 44,5\% de población ubicada en la zona de la integración precaria, un $12,5 \%$ en la de la exclusión compensada y un 5,8\% en el espacio de la exclusión severa (López Jiménez y Renes, 2011).

${ }^{7}$ Para un análisis pormenorizado de este proceso y su incardinamiento en el contexto europeo se puede consultar Laparra y Pérez Eransus (2012); Pérez Eransus (2013). 
capitalismo tardío, utilizando el conocido título del texto de Jürgen Habermas (1995), especialmente de sus instituciones políticas que han capitalizado el malestar derivado de la crisis ${ }^{8}$. En este sentido, uno de los objetivos de este texto será, precisamente, indagar en torno a este proceso de quiebra de legitimidades, considerar cómo se están produciendo los procesos de re-significación de las justificaciones del capitalismo y cuáles están siendo los vectores de deslegitimación en un proceso de reorganización y/o actualización de los discursos y cosmovisiones. Éstos justifican parcialmente el actual modelo y sus derivas, aunque, simultáneamente, tienden a ofrecer resistencias frente a dichas justificaciones.

La base constitutiva del estadio contemporáneo del desarrollo del capitalismo tardío es un enorme nudo de contradicciones ${ }^{9}$ que cada vez, en mayor medida, pasan de estar enmascaradas a manifestarse con toda crudeza, evidenciándose especialmente para algunos sectores sociales, precisamente aquellos más vulnerables. El grupo de personas y colectivos más afectados por la crisis (allí donde se manifiestan más agudamente sus turbulencias), que en este texto hemos denominado «nuevos pobres», es el que se encuentra en una posición liminar destacada, para tratar de componer un diagnóstico. Es precisamente este diagnóstico y la interpretación de sus posiciones discursivas lo que se pretende abordar en el presente artículo.

En este texto se utiliza el concepto de «nuevos pobres» o «nueva pobreza», siempre de una manera provisional (y entrecomillado), para referirse a los sujetos y grupos desestabilizados (Castel, 1999: 413) por los actuales acontecimientos derivados de las manifestaciones del capitalismo contemporáneo y sus crisis económicas (especialmente la que se está desarrollando en la actualidad) y que puede implicar - o no - la acción acumulada de otros factores exclusógenos. Se han considerado personas incluidas en la categoría de «nuevos pobres» a sujetos insertos en hogares que se han visto afectados por la situación de pobreza en los últimos años (a partir de 2007) procedentes de hogares caracterizados previamente por una cierta estabilidad (incluyendo, incluso, estabilidad en la precariedad) y unas condiciones económicas desahogadas. Así, se ha considerado como objeto de nuestra investigación a aquellos hogares con bajos - o nulos - ingresos, en situación de desempleo de todos sus miembros, o de subempleo en el caso del sustentador principal (hogares con ingresos procedentes exclusivamente de trabajadores pobres). Esta situación de pobreza se ha categorizado a partir de las dimensiones que son tenidas en cuenta en el indicador AROPE de Eurostat, esto es: poseer ingresos por

${ }^{8}$ Esta tendencia hacia una capitalización de los problemas de legitimación del capitalismo tardío (y sus recurrentes crisis) que se deslizan hacia la esfera política y hacia el papel ambivalente que los Estados pasan a desempeñar en dicho modelo es, precisamente, analizado en el texto de Habermas (1995).

${ }^{9}$ Como ya pusieron de relieve autores tan clásicos como Daniel Bell (1989) o Jürgen Habermas (1995). 
debajo del umbral de la pobreza relativa, sufrir privación en el hogar ${ }^{10} \mathrm{y} / \mathrm{o}$ tener muy baja intensidad de empleo a nivel del hogar que se considera ${ }^{11}$. En cualquiera de los casos, los miembros son seleccionados por su pertenencia a hogares caracterizados por su situación de pobreza sobrevenida en los últimos años. Es esta situación la que nos posibilita agregar el calificativo de «nueva» a la situación de pobreza que se considera. Dicha «novedad» habrá de ser evaluada a la luz de la evolución de las situaciones y trayectorias de los hogares considerados. Es esta característica la que imprime un especial interés a la investigación que se presenta, pero también la que convierte el concepto «nueva pobreza» en una categoría enormemente inestable.

\section{Antecedentes en el estudio de los procesos de subjetivación y la conformación de marcos interpretativos de lo social vinculados a la vivencia de la pobreza}

Dos han sido fundamentalmente las cuestiones clave que han atravesado el conjunto de las reflexiones en torno a la pobreza. Un primer objetivo, perseguido insistentemente, se ha dirigido a conocer cuántos y qué perfiles presentan los sujetos considerados pobres (con finalidades diversas de control, denuncia o planificación de la asistencia o de las políticas públicas). Es esta necesidad de conocimiento acerca de quiénes son los pobres (y cuál es su volumen) lo que ha caracterizado buena parte de las aproximaciones de corte cuantitativo a la pobreza, dando lugar a una proliferación ingente de censos, registros sistemáticos, macrooperaciones estadísticas a nivel de los estados y de grandes regiones, encuestas de menor alcance centradas en análisis de corte más local o sectorial, orientadas a la configuración de indicadores e índices que han tratado de dimensionar desde diferentes ópticas, y con diversos objetivos, el alcance de la problemática. También en el momento contemporáneo, la medición del alcance cuantitativo de los efectos de la crisis financiera global en el empobrecimiento de los hogares está concentrando buena parte de los esfuerzos analíticos de los estudiosos de las ciencias sociales (ver por ejemplo, FOESSA, 2013; Embid, 2013; Laparra y Pérez Eransus, 2010 y 2012; Salido, 2012 o López Jiménez y Renes, 2011).

${ }^{10}$ Definida por la imposibilidad de poder realizar cuatro de los nueve consumos básicos que se proponen como opciones en el indicador (pagar el alquiler o una letra, mantener la casa a una temperatura adecuada, afrontar gastos imprevistos, una comida de carne, pollo o pescado - o su equivalente vegetariano - al menos 3 veces por semana, unas vacaciones fuera de casa al menos una semana al año, un coche, una lavadora, un televisor en color y un teléfono - fijo o móvil-).

${ }^{11}$ Concretamente, que el hogar esté por debajo del $20 \%$ de las posibilidades de empleo en el índice de intensidad de empleo tal como se define por Eurostat para el indicador AROPE (INE-ECV, 2012). El 100\% sería cuando todos los miembros activos trabajan a tiempo completo y se va reduciendo cuando en el hogar hay desempleo o subempleo. 
Un segundo interrogante cardinal que atraviesa buena parte de la reflexión en torno a la pobreza, se centra en conocer cómo viven, cómo actúan y cómo son los integrantes de esta población considerada pobre. Si tenemos en cuenta que buena parte de las reflexiones históricas (así como de las leyes, estatutos y normas derivadas) realizadas en torno a la pobreza se han centrado en un intento de demarcar cuáles vendrían a ser los pobres que, según los estándares y las hegemonías de los diversos momentos, merecen ayuda y cuáles no — esto es, los pobres dignos y los indignos - , encontramos que este proceso de clasificación pasa por una atribución de características individuales que permita dicha segmentación. De los procesos de subjetivación de la pobreza, en estas primeras aproximaciones se entresaca precisamente la voluntad (o su ausencia) de integración de los sujetos analizados, priorizándose la óptica individual y moralizante de dicha aproximación al fenómeno.

En respuesta a este tipo de interrogante axial, una aproximación fundamental vendrá a ser la que se desarrolla en el seno de la denominada Escuela de Chicago a través de los análisis realizados por autores como Park, Suttles, Cressey, Wirth y White y sus estudios sobre los slums o barrios periféricos. Estas investigaciones instaurarán una tradición de estudios en los que se enfatiza el análisis de las estrategias, pautas de socialización, y elementos culturales localizables tras el fenómeno. En esta línea destacan las aportaciones que en los años 60 realizó Oscar Lewis $(1961,1964)$ en lo que ha venido a llamarse la tradición de estudios sobre la cultura de la pobreza, en los que se presta una especial atención a los propios códigos familiares, laborales y normativos, así como a sus estilos de vida, hábitos y vivencias. También se incide en las formas de afrontar la precariedad, de tejer redes sociales, así como a las pautas de socialización vinculadas a la reproducción de la pobreza. Todo ello se aborda prestando especial atención a las dimensiones biográficas, identitarias, normativas y valorativas relacionadas con dicha situación y con la marginalidad. En la mayor parte de estas aportaciones, encontramos una aproximación a la pobreza en términos de déficits de integración, vinculándola a los procesos de desadaptación, desorganización y desestructuración, problemas de hábitos y estilos de vida, inadecuación a las normas del grupo mayoritario, carencia de habilidades y/o capacidades. Nos encontramos ante lo que podríamos denominar un proceso de psicologización — culturalista - de la pobreza que implica también una cierta responsabilización del colectivo de personas pobres acerca de su propia situación $^{12}$.

En esta línea de aproximación, de carácter fundamentalmente culturalista y centrada en el tipo de rasgos, hábitos y formas de vida que caracterizan a la población pobre, se desarrolla también toda una línea de reflexión sobre lo que ha venido a denominarse la underclass, infraclase o subclase, para referirse a la pobreza urbana

${ }^{12}$ Desestructuración familiar, presentismo, resignación, falta de control de los impulsos, incapacidad de ahorro y previsión, son algunos de los atributos que se asignan a dicha cultura de la pobreza desde esta perspectiva. 
de las grandes ciudades norteamericanas a partir de las reformas del mercado de trabajo y los procesos de desindustrialización que caracterizaron los años 80 . A esta 'infraclase' se atribuye, también, una especie de 'subcultura' que es, en buena medida responsable de su mantenimiento en la situación de pobreza. En un abierto giro de carácter aún más moralizante e individualista que la anterior orientación, se describen sujetos caracterizados por carencias de cualificación, inactivos o en situación de desempleo de larga duración, generalmente pertenecientes a minorías étnicas, vinculados a formas variables de actividades delictivas y que se insertan en familias dependientes de las provisiones del Estado asistencial, sujetos a quien es necesario incentivar y disciplinar. A partir de ellos se acaban definiendo las características y formas de vida personales y grupales que les mantienen en la situación de pobreza y dependencia, con frecuencia asociándolos a una condena de las mismas $\mathrm{o}$, en muchas ocasiones en una aproximación, también moralizante, a sus virtudes.

Entre las muchas críticas que se han dirigido a estos planteamientos, se han destacado las limitaciones que ambas aproximaciones de carácter culturalista tienen a la hora de comprender el fenómeno de la pobreza. En general, estas críticas se centran especialmente en el descuido o minusvaloración que se hace de los elementos estructurales que condicionan de manera fundamental el desarrollo de las culturas y contextos de pobreza, así como su ceguera con respecto a cuestiones relacionadas con el «poder de clase», así como su obstinación en no tomar en cuenta la profunda y multifacética participación del Estado en la producción de marginación social y desposesión (Wacquant, 2012: 13).

En el contexto europeo, a partir de los años 70 del pasado siglo y de manera muy relevante tras los años 80 , con el trasfondo de la crisis del modelo fordista, el proceso de reestructuración tecnológica del proceso productivo, la desindustrialización y deslocalización de la producción, así como con la expansión de las políticas de contracción y asistencialización del Estado de Bienestar, se produce la eclosión del concepto de exclusión social ${ }^{13}$ para hacer referencia a los nuevos fenómenos que se estaban produciendo como consecuencia de las transformaciones recientes del capitalismo. No es el concepto exclusión social el único que surge para hacer refe-

${ }^{13}$ Se produce un cambio paradigmático fundamental con la aparición y consolidación de este concepto según el cual la responsabilidad de la situación vivida pasa a recaer sobre un tipo de sociedad exclusógena, más que sobre los individuos concretos, sus hábitos o subculturas. Así, de la exclusión social se repite - insistentemente- que es un fenómeno estructural, multidimensional, heterogéneo, complejo y dinámico, que pasa a englobar a las personas y grupos que se ven excluidos de la participación en los intercambios, prácticas y derechos sociales que constituyen la base de la integración social. La exclusión implica privación de derechos sociales fundamentales que puede desencadenar problemas de ruptura de los vínculos sociales y de cohesión social, haciendo, así, referencia a los impedimentos para el ejercicio de la ciudadanía plena. En general, el término tiende a focalizarse en torno a los sujetos que no cuentan con la protección que otros miembros de la sociedad sí tienen, es decir, que no están incluidos en las relaciones de solidaridad (Lenoir, 1984). 
rencia a los nuevos procesos de empobrecimiento que se están produciendo en el capitalismo a partir de la instauración del modelo post-fordista. También encontramos el concepto desarrollado por Paugam (2007) de pobreza descualificante, el de supernumerarios inempleables de Castel (1999) o el de marginalidad avanzada de Waqcuant (2007). Este cambio social y su correlato conceptual suponen, paralelamente, una multiplicación de las aproximaciones cuantitativas al fenómeno (en un intento de dar respuestas al primero de los interrogantes que anteriormente señalamos), al tiempo que se desarrollan también una multiplicidad de investigaciones que intentan abordar las dimensiones más subjetivas de estos procesos, especialmente centradas en dar respuesta a la segunda de las cuestiones básicas (cómo son los pobres y cómo viven). Así se acrecientan los intentos de vivificar aproximaciones locales o sectoriales al fenómeno a través del relato de estrategias de supervivencia, biografías, y mundos de vida de la población pobre, y más concretamente, de la que en este contexto ha pasado a denominarse población excluida. En esta línea, en los años 90 y primeros años 2000 asistimos a una eclosión de investigaciones de corte cualitativo que se ubican en estas coordenadas.

En el caso español, a pesar de sus manifiestas especificidades ${ }^{14}$, se multiplican las aproximaciones a la vivencia de la pobreza (y a la reconstrucción de sus estilos de vida, estrategias, formas de supervivencia, hábitos y actitudes) en las diversas Comunidades Autónomas, en los variados programas y/o instituciones de atención a las situaciones de pobreza (rentas mínimas de inserción, evaluación de planes de integración de diversos colectivos, Informes de Cáritas, o los informes de vulnerabilidad de Cruz Roja, Investigaciones de asociaciones como AMEI, Fundación Tomi1lo, RAIS, etc.), así como en los diferentes colectivos (mujeres, inmigrantes, jóvenes, población gitana, población reclusa o personas sin hogar, por poner algunos ejemplos).

Más allá de las aproximaciones a los estilos de vida, estrategias de supervivencia, hábitos y actitudes de la población pobre, o de aquellos colectivos considerados como tal, son pocos los acercamientos que se hacen al fenómeno de la pobreza considerando a los pobres como sujetos portadores, reproductores y configuradores de ideología — sujetos inevitablemente políticos, por lo tanto- y que conforman sus miradas sobre el mundo, sus cosmovisiones, a través de la construcción de marcos interpretativos de su situación y sus vivencias particulares, elaborados en un

\footnotetext{
${ }^{14}$ No hay que olvidar que la crisis del 73 y sus consecuencias en la generación de nuevos grupos de personas excluidas del modelo de bienestar coincide en el caso español, con un momento de apertura política y de desarrollo económico, así como con un avance insuficiente, fragmentado y asistencializado - del Estado de Bienestar que ha presentado especificidades profusamente analizadas (Navarro, 2006; Rodríguez Cabrero, 2004; Sarasa y Moreno, 1995); insuficiencias y modelo de desarrollo que, como se ha apuntado reiteradamente, constituyen algunos de los factores más relevantes que ayudan a comprender la enorme incidencia de la crisis actual en la población española, y en especial, en los sectores más vulnerables.
} 
contexto social específico, donde tales ideologías y marcos interpretativos circulan. No podemos localizar en la literatura especializada un cuerpo específico de textos y debates que sirvan como base para establecer el estado de la cuestión relacionado con este tercer interrogante - clave, como los otros dos, desde nuestro punto de vista - Sí se localizan, no obstante, acercamientos puntuales (generalmente en obras con temática amplia acerca de las situaciones de pobreza) a las consideraciones que los diversos grupos de pobres hacen en relación a la pobreza, su propia situación de pobreza, la percepción de sus necesidades o de las instituciones públicas y privadas con las que han de bregar en el desenvolvimiento de su cotidianeidad. Aquí podemos ubicar, por ejemplo, los textos de Narayan (2000, 2002a y 2002b), Narayan, Chalmers et al. (2002), Duschaatzky y Corea (2002).

Seguramente, la aproximación que, en mayor medida, puede vincularse con este tipo de interés investigador es la que se propone en la obra colectiva que dirigió Bourdieu (1999), sobre La miseria del mundo. En esta obra, vinculando la pobreza a los procesos de desestructuración de la clase obrera y sus mundos de sentido, Bourdieu y sus colaboradores - a partir de una análisis de la complejidad de acciones, posiciones y contradicciones - desarrollan profusamente, a través de una multiplicidad de entrevistas, cómo se manifiesta la crisis de conciencia de clase, la experiencia de inferiorización y construcción vinculada de identidades negativas, el desconcierto y falta de expectativas generadas por los nuevos contextos, así como los efectos de la violencia estructural del sistema contra los sujetos en estas posiciones. En este texto se abordan las manifestaciones de los procesos de dominación en las propias cosmovisiones de los sujetos pobres, así como de la miseria de posición (Bourdieu, 1999: 10) y la reproducción simbólica de las condiciones de pobreza ${ }^{15}$. En esta línea podríamos referirnos a las reflexiones de Castel (1999) sobre cómo la existencia en las sociedades contemporáneas de "supernumerarios inempleables" provoca que dichos sujetos y la "inutilidad social en la que están instalados" (dado el déficit de lugares ocupables) queden también descalificados en el plano cívico y el político. Señala este autor, cómo a diferencia de los grupos subordinados de la sociedad industrial - explotados pero indispensables - los nuevos excluidos "no gravitan en el curso de las cosas" (1999: 416). Hablará así de "no fuerzas sociales" o de "normales inútiles" (ibíd.). En este sentido, la resistencia supondría, señala este autor, la existencia de un colectivo y de un proyecto de futuro. En este contexto, se pueden generar nuevas sociabilidades flotantes, pero que ya no gravitan en torno a apuestas colectivas. Como apunta Castel (ibid.: 445), la constitución de una fuerza de protesta y transformación social supone la confluencia, por lo menos, de tres condiciones: una organización estructurada en torno a una condición común, un

${ }^{15}$ El análisis de estas condiciones de reproducción, así como la importancia de considerar las relaciones entre los diversos capitales poseídos por los sujetos, y en el caso de las poblaciones pobres, especialmente entre capitales sociales y políticos ha sido también analizado por Alicia Gutiérrez (2004a y 2004b). 
proyecto alternativo de sociedad y el sentimiento de ser indispensable para el funcionamiento de la máquina social. Como señala Castel, los supernumerarios de hoy no satisfacen ninguna de estas condiciones: están atomizados, no pueden albergar otra esperanza que la de ocupar un lugar un poco menos malo en la sociedad actual $\mathrm{y}$, además, son etiquetados como socialmente inútiles — condición que terminan asumiendo-. Señala, para concluir, que otra posibilidad de reivindicación, no organizada, es la que responde con violencia (vandalismo, delincuencia, consumos adictivos, etc.), que para este autor, se desarrolla, casi siempre, sin proyecto y que es, al mismo tiempo, autodestructiva.

De regreso a nuestro contexto concreto actual, con la irrupción de la crisis económica a partir de final del 2007, se han multiplicado las aproximaciones dimensionadoras de sus efectos, encontrando una multiplicidad de estudios que comienzan a dar cuenta de las cambiantes condiciones de vida de la población española, y de la caracterización de los procesos de empobrecimiento que han tenido como corolario. Son escasas, por el momento, las aportaciones que se relacionan con el conocimiento y la reflexión en torno a las estrategias de supervivencia y los estilos de vida que se están generando en la población más afectada por dichos acontecimientos, y, menos aún, se localizan aproximaciones a la incidencia que estos procesos están teniendo en el nivel ideológico y las cosmovisiones de las personas directamente afectadas por el proceso. Un abordaje en esta línea, lo podemos encontrar en el artículo de Alonso et al. (2011) para el caso de la población española en su conjunto (no solo para la más empobrecida) a partir del análisis del discurso de una serie de grupos de discusión, donde estos autores entresacan de manera fundamental la acción combinada de la culpabilidad hacia la que parecen orientarse los discursos localizables y los efectos disciplinantes de los procesos de precarización creciente de la población en su conjunto. Algunas aproximaciones a la incidencia que la situación de "nueva pobreza" está teniendo en el nivel ideológico y en la conformación de identidades políticas puede localizarse en varios estudios en el contexto latinoamericano (ver por ejemplo, Kaztman, 2001; Merklen, 2005; o Castillo Gallardo, 2011) donde encontramos importantes esfuerzos tanto teóricos como empíricos a la hora de analizar las relaciones entre pobreza y ciudadanía, y las vinculaciones entre las representaciones sociales en torno a la política y las grandes transformaciones en la estructura social - especialmente en lo que se refiere a los procesos de empobrecimiento- de las últimas décadas. Por otra parte, en el norte del continente americano se multiplican las investigaciones centradas en analizar los procesos de aislamiento y desapego a "la comunidad" que acompañan a las situaciones de pobreza (Stewart et al., 2009; Hatfield, 2004; Green y Rogers, 2001). 


\section{Objetivos y metodología}

En este artículo, se trata de profundizar en los elementos ideológicos ${ }^{16}$, concretados en lo que hemos venido a denominar marcos interpretativos de lo social, en el colectivo concreto de aquellos que hemos llamado «nuevos pobres», es decir, colectivos en situación de pobreza sobrevenida a partir de los últimos procesos de reestructuración social que han acompañado a la crisis económica contemporánea. Nos interesa conocer cómo este sector de sujetos "desestabilizados", empujados desde la zona de la estabilidad/integración o la vulnerabilidad hacia la de la precariedad, exclusión y pobreza (en términos de las zonas teorizadas por Castel, 1999), construyen su posicionamiento frente a diferentes aspectos clave relacionados con lo social - mitos sobre la organización social, desigualdad, posicionamiento de los agentes sociales frente a los procesos de polarización social y el empobrecimiento, etc.- , cómo desde esos espacios de precariedad, quiebra de su mundo conocido y de sus identidades, dan sentido a su situación y a la de otros individuos en situaciones similares.

Pretendemos aproximarnos a algunas claves de comprensión de los procesos de legitimación de los nuevos procesos de empobrecimiento de amplias capas de la población española, a cómo operan los dispositivos de justificación de las tendencias a la precarización de las condiciones de vida (asociadas a la privación, la desprotección...) que caracterizan las formas sociales contemporáneas. También nos interesa desvelar las diversas respuestas que se construyen frente a estas tendencias, y que pueden contribuir a cuestionar las formas que contribuyen a su subordinación y dominación. Conocer estos procesos y dispositivos ideológicos, y observar cómo se articulan los discursos sociales, puede proporcionarnos algunas claves para considerar las fracturas, así como las contradicciones, las respuestas articuladas o posibles, que subyacen a las formas actuales de reproducción del modelo contemporáneo del capitalismo global.

El trabajo que aquí se expone arranca de una serie de conjeturas básicas que nos han ayudado tanto a perfilar el diseño técnico del material empírico utilizado en la

\footnotetext{
${ }^{16}$ Somos conscientes de la vaporosidad del concepto ideología que tan diversos - y en ocasiones contrapuestos - significados ha tenido a lo largo de la Historia reciente. En este texto utilizamos el concepto de ideología, no en el sentido de pre-nociones, ni de la hegeliana consideración como conciencia desgraciada, o de la falsa conciencia marxiana, sino en el sentido en el que Therborn (1987) lo usa, haciendo referencia a visiones del mundo y de las cosas que se asientan en cómo se percibe desde las — complejas - posiciones sociales que se ocupan, y que cristalizan en órdenes de discursos que circulan y son actualizados por grupos diferentes, y que frecuentemente permanecen en conflicto por imponerse. Se relaciona con cómo percibimos, pero también con cómo valoramos, qué consideramos justo o injusto, verdadero o falso, existente o no existente, valorable o desdeñable y posible o imposible.
} 
investigación, como la elaboración de los guiones que han servido de base para el desarrollo del trabajo de campo, así como a la hora de organizar el análisis de los materiales así obtenidos.

Insistimos en la caracterización del espacio social de la «nueva pobreza» como un espacio que muestra una elevada heterogeneidad. Esta heterogeneización de la pobreza vendría a caracterizar al nuevo sector social que se constituye en el contexto de procesos de desregulación, concretándose en una dinámica de descomposición de clases más que de su consolidación. Como señala Wacquant, este proceso se produce "bajo la presión de una doble tendencia a la precarización y a la desproletarización, en lugar de la homogeneización proletaria en las regiones inferiores del espacio social y urbano" (2007: 283). Para este autor, en este contexto se produce una proliferación de etiquetas que se supone designan a poblaciones dispersas y dispares, prisioneras del estado de marginación social y espacial ${ }^{17}$ lo que, entre otras cosas, ilustra la desregulación simbólica que afecta a los colectivos sociales, y explicita las fisuras de la estructura social y urbana. Así, el grupo de sujetos a los que hemos denominado «nuevos pobres» permanecería en un estado de "simple aglomeración compuesta, integrada por individuos y categorías heterogéneas entre sí, y definidas negativamente por la privación social, las carencias materiales y el déficit simbólico" (ibídem: 285).

Por otra parte, se apunta la existencia de posicionamientos discursivos que atraviesan (y, que por lo tanto, son básicamente compartidos) las diferentes categorías que integran el heterogéneo espacio social de la «nueva pobreza». Pero, al mismo tiempo, se postula la existencia de elementos ideológicos diferenciales en el seno de las diversas categorías sociales que conforman el fenómeno de la «nueva pobreza». Son diferencias que se asientan en la diversidad de habitus de clase, combinaciones de capitales disponibles y posiciones socio-estructurales que caracterizan dichas categorías, y que además, se transforman dinámicamente.

Por último, una tercera conjetura que ha guiado nuestro análisis cualitativo se centra en torno a la emergencia paradójica de elementos re-actualizadores del discurso legitimador de las instituciones políticas y económicas que se pueden localizar en el discurso de los «nuevos pobres». Así, pensamos que se está produciendo un proceso de actualización y redefinición de la legitimidad del modelo, en un contexto de profunda transformación material, social e ideológica. Por otra parte, y de forma paralela, se postula que el surgimiento de espacios de contestación al discurso legitimador del modelo hegemónico encuentra resonancias y reinterpretaciones diversas en el conjunto de los «nuevos pobres».

Para intentar abordar los objetivos del presente texto, se aborda el análisis de las producciones discursivas de sus protagonistas, su "hablar" colectivo. Para ello, se

${ }^{17}$ Etiquetas como "nuevos pobres", “zonards", “excluidos", “underclass", "jóvenes de los suburbios" y la trinidad de los "sin" (sin trabajo, sin techo, sin documentos)" (Wacquant, 2007: 284). 
analiza el material empírico de una investigación desarrollada en el ámbito de la Comunidad de Madrid y subvencionada por la CM y la UCM. Dicho material empírico se concretó en la realización de seis grupos de discusión, dos grupos triangulares y ocho entrevistas abiertas a personas que reúnen los requisitos asociados a lo que hemos denominado «nueva pobreza». En el diseño de la investigación, se ha atendido a los procesos de heterogeneización de la pobreza y, por tanto, se ha recurrido a criterios de diversificación socio-estructural para reconstruir las diversas y heterogéneas posiciones desde las cuales se vivencia el proceso y la situación de empobrecimiento. Los criterios de diversificación de las posiciones considerados han sido la clase social de partida - atendiendo también al origen social de los progenitores-, el nivel educativo, la posición previa y actual en el mercado de trabajo y en el proceso productivo, el género, la edad, el nivel de ingresos y el acceso a prestaciones, la nacionalidad y la condición inmigrante, la situación en relación con la vivienda (propiedad, alquiler, acogimiento familiar, desahucio...), así como la situación familiar ${ }^{18}$. El trabajo de campo se ha realizado a lo largo de año y medio, de forma que en una primera fase, entre mayo-junio de 2011, se celebraron los grupos de discusión y en una segunda fase, comprendida entre juliooctubre de 2012, se llevaron a cabo las entrevistas y los grupos triangulares, allí donde sobre los primeros análisis pudimos localizar huecos discursivos o espacios sin explorar. Este desarrollo a lo largo del tiempo, nos ha permitido considerar la evolución del proceso de empobrecimiento, en el contexto del desarrollo de la crisis, así como observar el entronque y posicionamiento de este conglomerado social en relación a los movimientos de protesta que han emergido durante este tiempo; por último, ha facilitado el análisis y la reflexión sobre los posicionamientos discursivos en su dinamismo y su transformación — acelerada - en un contexto de cambio vertiginoso.

\section{Marcos interpretativos de lo social en el caso de los «nuevos pobres»}

El concepto de «marcos interpretativos» que aquí se utiliza hace referencia a conjuntos heterogéneos y dinámicos de elementos articulados en forma de argumentos, explicaciones, mitos, metáforas, espacios semánticos y estilos discursivos ${ }^{19}$, que emergen de forma recurrente en el discurso de los sujetos y grupos - en términos foucaultianos, en sus prácticas discursivas- . Estos elementos contribuyen a conformar miradas, posicionamientos, valoraciones y actuaciones particulares sobre

${ }^{18}$ La configuración concreta del material empírico se expone en el anexo donde se desarrolla la ficha técnica de la investigación.

${ }^{19}$ La construcción de espacios semánticos y estilos discursivos son algunas de las herramientas que Fernando Conde (2009) propone como elementos clave a la hora de proceder en el llamado "análisis sociológico del sistema de discursos". 
el mundo (el mundo social en esta ocasión), sobre la forma en que se organiza la sociedad, sobre los atributos, problemas y conflictos que la caracterizan, así como sobre la atribución de responsabilidades en relación a los problemas que se generan. Este concepto deriva tanto de las aportaciones de Wetherell y Potter (1988) en relación a lo que estos autores denominaron «repertorios interpretativos», como de la metodología del Frame Analysis y los «marcos de la experiencia» atribuido de forma general a Goffman (2006), que este autor utilizó para analizar cómo las personas entienden las situaciones y actividades en su vida cotidiana. Esta metodología ha sido aplicada en muy diversos ámbitos estando en la base del análisis de los marcos conceptuales utilizado por George Lakoff (2007) a la hora de interpretar el lenguaje político y sus metáforas.

Así pues, desde nuestra perspectiva, los marcos interpretativos conforman el espacio de las comprensiones y explicaciones sobre el mundo social, pero también se conforman como espacio de las prácticas sociales, $\mathrm{y}$, en ese sentido, no constituyen un mero contrapunto mental a las mismas. Por otra parte, las vivencias subjetivas y sus narraciones, lejos de constituirse en una especie de asunto personal, remiten a las esferas sociales y culturales y a posiciones sociales colectivas.

No encontramos, ni mucho menos, un espacio discursivo uniforme y monolítico (si bien es fácil identificar importantes núcleos de sentido compartidos). La diversidad se muestra relacionada con la elevada heterogeneidad estructural que presenta el colectivo de referencia, que condiciona sus estrategias vitales y que constituye la base de buena parte de sus marcos interpretativos sobre lo social. Por otro lado, hay que señalar el carácter multidimensional que reflejan los marcos interpretativos y los modelos explicativos sobre lo social, y la frecuente ambivalencia e, incluso, inconsistencia discursiva que recorren nuestros grupos y entrevistas. Estas inconsistencias, ponen de relieve la incipiente emergencia de discursos en proceso de consolidación y cristalización social, que proyectan representaciones que tratan de acoplarse dinámicamente a un contexto socioeconómico en proceso de profunda transformación a lo largo de los últimos años. Los grupos ensayan en sus discursos modelos explicativos multidimensionales y no necesariamente congruentes. Por otra parte, los grupos y sujetos entrevistados se ubican recurrentemente en posiciones discursivas en muchas ocasiones contradictorias y tremendamente inestables, inestabilidad en la que las posiciones y los roles se desplazan constantemente de unos espacios a otros, ensayando posicionamientos que pueden entrar en armoniosa contradicción. Los discursos que se ponen en juego se activan y reproducen en relación a experiencias y situaciones concretas, con intencionalidades variables y, por tanto, admiten ambivalencia y contradicción.

A continuación se examinan, básicamente, los elementos localizados en el material discursivo que conforman los marcos interpretativos, y que están presentes (con variantes e intensidades diversas) en el conjunto de los sujetos y grupos considerados. Articulamos estos elementos en tres grandes bloques; uno relacionado con el debilitamiento del entramado mítico que ha contribuido a asentar y legitimar el modelo capitalista, en segundo lugar, se analiza el lugar tópico de la responsabilización individual asentada en la argumentación en torno a los "excesos de consumo" 
como elemento básico que re-significa los procesos de atribución causal de la situación de carencias y pobreza. Dicha argumentación experimenta transformaciones, matizaciones y dinamismos que serán considerados. Por último, se aborda el espacio común de la autocensura del malestar generado por la situación vivenciada de pobreza por parte de este colectivo.

\subsection{Debilitamiento del entramado mítico del modelo capitalista}

A partir del trabajo de campo realizado en la investigación que aquí se referencia se puede afirmar que en el caso de los «nuevos pobres», entramos en un momento en el que se producen de forma acumulada un profundo debilitamiento, a nivel discursivo, de buena parte de los principios axiales que han caracterizado la modernidad, de manera que se puede atisbar el inicio de una profunda crisis $^{20}$ de legitimidad del modelo social y económico. Es decir, el parapeto ideológico del modelo de desarrollo capitalista, aun siendo muy sólido - y esto se comprueba reiteradamente en el trabajo de campo- se está resquebrajando (parcialmente) dada la contundencia de la crisis y su prolongación en el tiempo, así como la incidencia directa de sus consecuencias materiales, especialmente en este sector de la sociedad. Esta fractura ha facilitado la aparición de posiciones discursivas novedosas (o que previamente tendían a ocupar una posición residual).

En este sentido, cabe decir que se está produciendo un intenso debilitamiento del entramado sustentado por alguno de los principales mitos fundantes de la modernidad: el mito del progreso, el de la meritocracia, el de la sociedad de clases medias, el de la democracia representativa, así como de las aspiraciones generalizadas de acceso al consumo como forma básica de integración social.

\section{La ruptura parcial del mito del progreso}

Resulta interesante considerar el debilitamiento severo del discurso mítico del progreso, que cuestiona en el extremo la posibilidad de futuro y que, en general, reconoce un porvenir incierto que no necesariamente será mejor. Muy al contrario, se percibe un proceso de empeoramiento, de manera que se acentúa el desarrollo de estrategias y discursos regresivos, de repliegue defensivo, descreídos y escépticos, y, en el extremo, autodestructivos.

Se desarrolla en los grupos y entrevistas una reflexión de carácter histórico sobre lo que ha supuesto el momento actual en unas vidas proyectadas a partir de la creencia en la mejora constante a través del esfuerzo y el trabajo. Se remiten a la figura de los padres y a su lucha cotidiana por acceder a los beneficios de dicho

${ }^{20}$ Entendemos en este sentido el concepto de crisis cuando los miembros de una sociedad experimentan los cambios de estructura como críticos para el patrimonio sistémico y sienten amenazada su identidad social (Habermas, 1995: 18). Para este autor las crisis sociales solo pueden comprobarse en fenómenos de conciencia de modo que la integración social resulta amenazada. 
progreso, y se lamenta la situación de frustración generada sobre el fracaso de dicha proyección. En los relatos se localizan básicamente tres momentos clave en las reconstrucciones de la creencia en el mito que son actualizados por los sujetos.

Se señala un primer momento atribuido a las vivencias de juventud o infancia y, en el caso de los jóvenes, al relato de los progenitores, que correspondería a los años 60,70 y primeros 80 de la historia reciente de nuestro país. A esta época se atribuyen vivencias de privaciones familiares, problemas económicos más o menos graves y consumos muy contenidos que llevaban a desarrollar una especie de ingeniería financiera en el hogar para poder llegar a final de mes y acceder a un paquete "básico" de bienestar. A pesar de las penurias, el mito del progreso (tanto político como económico) atravesaba la consideración básica del modelo social y político que les estaba tocando vivir. Había posibilidad de encontrar trabajo, relativamente estable, con ciertas garantías. Insertos en un contexto de contención máxima del consumo se hacía un sobreesfuerzo de trabajo (multiplicándo, por ejemplo, el número de horas extraordinarias) y ahorro, para acumular algún pequeño capital que permitió acceder, en muchos casos, a la vivienda en propiedad, y que quedó parcialmente acumulado en los bancos, en forma de activos financieros o en la compra de un terreno sobre el que más tarde se levantaría una casa, o en una rehabilitación de una vivienda en el lugar de origen $^{21}$. En este momento se produce la apertura política hacia el modelo de democracia liberal consiguiendo sumar al mito del progreso económico el del progreso político. Además, un incipiente, aunque muy limitado, desarrollo del Estado del Bienestar en los últimos años intensificó la confianza en ese modelo de desarrollo que facilitó un acceso masivo a la educación - incluso la universitaria - a la sanidad y una limitada cobertura para las situaciones de carencia y necesidad (con un desarrollo raquítico de los servicios sociales y la consolidación de los sistemas de garantía de rentas). A este momento se atribuye también la posibilidad de desarrollar un trabajo "bien hecho" y profesional en un contexto de cierta estabilidad y garantías laborales.

Se aprecia un segundo momento, vivido ya directamente por la totalidad de los sujetos que constituyen nuestro objeto de estudio, que correspondería a los años 90 y comienzos de los 2000 hasta la llegada de la crisis económica. A este periodo se atribuye un agudo crecimiento económico ("la época de bonanza") vinculándolo

${ }^{21}$ Son estos pequeños ahorros y sus materializaciones concretas los que en el momento actual están sufriendo un proceso de uso intensivo por parte de entidades financieras, y por parte de las generaciones de jóvenes y adultos afectados por la crisis actual, insertos en un fuerte proceso de empobrecimiento. La ayuda de los padres, los suegros, los abuelos, la vivienda que adquirieron, junto con las pensiones - más o menos garantizadas - están sirviendo de colchón básico para amortiguar los efectos de la crisis de las generaciones posteriores. Con ello, se está produciendo un profundo proceso de descapitalización de estas generaciones de trabajadores que basaron su vida en el duro trabajo y la contención ascética, asentados en la creencia en las promesas de ese mítico progreso y el acceso posible al ansiado bienestar. 
fuertemente en el desarrollo del sector de la construcción ${ }^{22}$. Durante estos años se incrementaron intensamente las rentas disponibles de una parte muy importante de las familias que accedieron masivamente - y sintieron la seducción - a los modelos de consumo. A pesar del crecimiento económico sostenido que se produjo, las condiciones de trabajo - la inestabilidad y la desregulación - fueron aumentando paulatinamente en términos generales, afectando de manera más dramática a los jóvenes que se incorporaban al mercado de trabajo, pero no solo a ellos (una parte importante de los sujetos que componen nuestro trabajo de campo, sufrieron este proceso de transformación, otros, los más jóvenes se incorporaron directamente en este modelo desregulado y precario). El empleo generado, y al cual accedieron una parte importante de los sujetos ahora encuadrados en «la nueva pobreza», se caracterizaba por la precariedad, pero la sensación en los grupos es de que existía abundancia de puestos de trabajo. Así, la mayor parte de las personas que han constituido la base de nuestro trabajo de campo, narran la vivencia de su experiencia laboral en estos años vinculándolo a situaciones de relativa opulencia, consumos "normalizados" y bienestar, aunque también relatan frecuentemente condiciones de gran precariedad, rotación y flexibilización, si bien estas no eran vividas de forma angustiosa dada la abundancia de empleos, generando una instalación en la precariedad vivenciada como cuasi-estabilidad ${ }^{23}$. Los jóvenes pasaron a disponer tempranamente de ingresos y a incorporarse masivamente a la dinámica de un consumo con manifestaciones más voraces que las de sus progenitores. Paralelamente las arcas del Estado consiguieron amplias recaudaciones con las que se logró subvencionar importantes infraestructuras, engrosar algo más el sector público y continuar consolidando la cobertura del desempleo y las políticas de garantía de rentas. Esto permitió a muchas personas acceder a puestos de trabajo relativamente estables, y a otros muchos, deambulantes vulnerables, pasar de la precariedad a la situación de desempleo, y de este desempleo, de nuevo a la precariedad en condiciones menos dramáticas, con una asentada creencia en la posible mejora constante. En este contexto, la creencia en el progreso se consolidó aún más y, en general, las personas pasaron a considerarse miembros de una clase media - así se afirman la mayor parte de los sujetos - cada vez más extensa (capaz de consumir, invertir y en muchos casos también ahorrar), y que reposicionaba al país en una carrera por situarse entre las potencias económicas del entorno europeo. El mito del bienestar y del progreso se consolida a pesar de la tremenda precariedad sobre la que se estaba construyendo, y a pesar del proceso de dualización y polarización social que presentó el modelo de

${ }^{22}$ El protagonismo de la internacionalización del capital, de manera fundamental del financiero, durante este periodo, pasa prácticamente desapercibido por los grupos y sujetos que participaron en nuestro trabajo de campo.

${ }^{23}$ Incluso se produce un proceso de mitificación de esta época a la que se atribuye bienestar, posibilidades de elección de puestos, de salarios, de destinos. 
desarrollo económico ${ }^{24}$. Este momento es condensado en un "antes" mitificado que atraviesa los discursos en el momento actual y que se percibe muy lejano ("antiguamente...." señalan apuntando a este momento algunos de los miembros de los grupos y entrevistas).

Con la llegada de la crisis a finales de 2007 se entra en un momento caracterizado por la quiebra absoluta de este modelo de desarrollo económico. Pasamos a un estadio asentado, en buena medida, en la precariedad de los puestos de trabajo generados, y se produce un fuerte desplazamiento en todos los sectores hacia puestos con menores sueldos, mayor temporalidad, menor regulación (multiplicándose el empuje hacia ciertos espacios de la economía informal e, incluso, como aparece en nuestros grupos reiteradamente, situaciones de trabajo sin ninguna remuneración), y con ello, aumenta la presencia social de trabajadores pobres y desempleados, con accesos muy disputados a los pocos espacios informales que toman la forma de ocasionales "chapuzas".

Destaca, en la puesta en escena de los grupos y entrevistas, un importante proceso de quiebra del imaginario promocionista y de la confianza en la mejora constante (y el futuro previsible) a través de la vía del desarrollo económico — no así del tecnológico- que ha caracterizado las últimas décadas. Esta conciencia se ve agudizada por los intensos procesos de recorte que se están desarrollando en los últimos años y que afectan a todos los ámbitos relacionados con el bienestar social, recortes que afectan de manera mucho más dramática a estos sectores caracterizados por la privación, para los que la retirada de una beca de comedor, una disminución de la prestación por desempleo, o el tener que pagar una medicina, o no acceder a una ayuda de los servicios sociales, puede significar la imposibilidad de satisfacer la básica necesidad de la alimentación.

Se asiste a una cierta materialización de la conciencia del cambio vertiginoso, una transformación que se desarrolla de forma acelerada y brutal. En este sentido, desde el primer momento, el conglomerado de «nuevos pobres» articula su hablar colectivo en una constante comparación entre un antes (que se desarrolla bajo el espejismo de la seguridad, el equilibrio y la confianza, caracterizado por una cierta posibilidad de previsión del futuro) y un ahora desbocado, inseguro, desesperanzado, caracterizado por la incertidumbre, que los ubica en una situación de "caída"

\footnotetext{
${ }^{24}$ Este proceso de dualización y polarización que se estaba desarrollando en este periodo pasa prácticamente desapercibido para el conjunto de sujetos que conforman nuestra base empírica, los cuales toman conciencia del mismo, cuando éste les afecta personalmente. También está ausente de los discursos la conciencia de la existencia de programas de protección muy residuales, atomizados y poco dotados por parte del Estado y de las autonomías, orientados a mitigar las consecuencias más dramáticas de los novedosos espacios de exclusión social. Tampoco se evidencia en los discursos el desarrollo de programas puestos en marcha por ONGs y asociaciones de diverso carácter. En buena medida, los espacios de la carencia y la privación en este segundo momento narrado permanecían ocultos (exceptuando su visibilidad en las calles, en los casos de la exclusión social más extrema).
} 
libre en un abismo vertiginoso. Esta crisis del mito del avance constante se ve actualizada en, prácticamente, la totalidad de los discursos, donde no solo se habla del modelo regresivo en relación al idealizado progreso, sino que se incide en la velocidad con la que ese proceso se está desarrollando. No obstante, hay que considerar que esta conmoción sobre la creencia en el progreso, fundamentalmente económico, no afecta en ninguna medida al discurso del progreso tecnológico que sale indemne de la sacudida del mito.

A pesar del debilitamiento del mito que atraviesa al heterogéneo colectivo de «los nuevos pobres», hay que señalar que dicha quiebra se manifiesta de forma matizada según los colectivos. En algunos casos, especialmente en los sujetos de clases medias bajas, los jóvenes cualificados y los profesionales, permanecen operativas - aunque de forma ambivalente-, las esperanzas de recuperar el modelo ansiado y perdido. Aunque aparecen referencias al desarrollo económico comprendido en forma cíclica y a la creencia (formulada de forma no muy convincente) de que el presente ciclo habrá de terminar, para retornar a situaciones mejores. Dichas referencias aparecen tintadas constantemente de ambivalencias, dudas, comentarios de descreimiento o de lapsus que apuntan hacia la falta de convencimiento ${ }^{25}$. En este subsector surgen referencias a la posibilidad de cambio en un sentido evolutivo del progreso para ser inmediatamente negados. La reiterada afirmación acerca de que "esto no puede seguir siempre asi" constituye una retórica vacía y negada en el desenvolvimiento del discurso. Buena parte de las metáforas que aparecen en el despliegue de los grupos y entrevistas, tienen que ver, precisamente, con esta ubicación en el borde o en el filo de un espacio que se agota, frente al cual no se contemplan alternativas y en el que se perciben arrastrados por unas fuerzas (fundamentalmente de carácter político) irresponsables, ciegas e incompetentes que "conducen al abismo". Así, el modelo social y económico en el que se ven inmersos se percibe como un modelo que "va a la deriva", "sin ningún rumbo" y en el que "nadie, ni nada está tomando las riendas", a lo cual se suma una percepción de que "cuando alguien las toma, lo hace para utilizarlo en beneficio personal" (GD3). Se multiplican las metáforas del automóvil, símbolo privilegiado del progreso, que ahora se transforma en símbolo del descontrol, de la falta de rumbo y del movimiento cargado de peligrosidad. Cuando se piensa en el futuro, las referencias se cargan de la negatividad y el miedo a que las cosas vayan todavía peor. Estos temores a un futuro todavía peor justifican, en buena medida, la ausencia de acción colectiva o, incluso, de iniciativas críticas (censurándose, incluso, la propia posibilidad de queja). Así, se enfrentan a un presente desalentador y a un futuro con escasas esperanzas, que pasa, en muchos casos, por la expectativa de la huida individual hacia la

${ }^{25}$ En este sentido, es muy interesante la aparición de determinados lapsus como el que aparece en uno de nuestros grupos (GD3), al hacer referencia al término "círculos" en lugar del de "ciclos", incidiendo más en el hecho de parecer estar estancados o dando vueltas sobre el mismo espacio. 
movilidad migrante, el retorno de los que llegaron como inmigrantes o, incluso, la vuelta a espacios de autoconsumo y a un mítico regreso al espacio rural que se ubica más en un plano idealizante que en proyectos concretos. Encontramos también, en este posicionamiento ambivalente entre la espera acechante y la huida escapista, un sector de jóvenes descualificados, muchos de ellos obligados al retorno al hogar paterno, que llenan su presente expectante a través del consumo desmercantilizado de ocio en el hogar (abundando en procesos de aislamiento en relación con el entorno).

En otros sectores de los aquí denominados «nuevos pobres» se produce una instalación en un presente multimovilizado que activa el tradicional "vivir al día" en una búsqueda incesante de ayudas, recursos, "chapuzas" que ubican en la incertidumbre vital, sin posibilidades ni espacios para pensar el futuro. Es precisamente el sector de las mujeres con responsabilidades familiares, así como el sector de la población inmigrante que ha conocido previamente las situaciones de privación, los que en mayor medida se instalan en este presentismo ciego al futuro (el futuro no se alcanza a vislumbrar o "no se ve"26, pero no se niega, o se da por perdido como sí ocurre en el caso de otro sector de los «nuevos pobres»).

Así, frente a quienes esperan un cambio de ciclo, o a quienes se instalan en el presente ciegos al futuro, se localiza un sector de los «nuevos pobres», más presente en el grupo de obreros maduros que podemos ubicar en el espacio del acabamiento, toda vez que desarrollan posicionamientos frente al futuro que consisten en sentir que han llegado a una estación términi, o que han terminado por "caer en un pozo" (GD2), del que ya difícilmente van a salir. El tono vital de estos grupos y sujetos se encuentra en este posicionamiento arquetípico, el de sentirse simplemente acabados desde una perspectiva laboral y vital. "El pozo" o "la lenta agonía desesperada" o "los muertos vivientes" serían metáforas que condensan este tipo de actitud arquetípica; son los inempleables del modelo, autoubicados y etiquetados como "inútiles" sociales (de los que ya hablara Castel), sujetos que no esperan nada, ni proyectan nada, simplemente porque se saben acabados ${ }^{27}$.

En general, para todos estos subsectores, la reforma en la edad de jubilación y de las condiciones de acceso a las pensiones, así como la conciencia de la escasez de posibilidades de contribuir a la Seguridad social, dada su dificultad de acceso al mercado de trabajo o las condiciones de su acceso precario — sin apenas cotizacio-

${ }^{26}$ De hecho, la presencia de los hijos en los hogares supone, especialmente para las mujeres, la materialización del futuro en sus personas, que vivifican proyectos y por lo tanto, impulsan hacia esa supervivencia multimovilizada.

${ }^{27}$ Quizá, es este uno de los aspectos más duros de su situación, ya que ubicados en un tipo de mentalidad instrumental (en "el hacer") se ven condenados a una parálisis inhabilitante que, cada vez más, resalta su inutilidad; al mismo tiempo su recogimiento en el hogar es vivido como una especie de travestismo humillante que, nuevamente, cuestiona su masculinidad; el hogar sería para ellos un «no lugar» en términos de Augé (2008: 88) que no puede definirse ni como lugar de identidad, ni como relacional, ni como histórico. 
nes - refuerza esta sensación de no tener un posible futuro cubierto a través de una pensión, que se convierte en angustia existencial presente.

\section{La crisis del ideal meritocrático y de la igualdad de oportunidades}

Por otra parte, se evidencia también un importante debilitamiento de la confianza en el ideal meritocrático. Se reconstruye de una forma idealizante un pasado perdido en el que el saber, la experiencia y el trabajo bien hecho ("el buen profesional") encontraba siempre su espacio. En cambio, en el momento actual, los criterios del éxito —o la simple integración precaria - a través del acceso al trabajo, pasan necesariamente por elementos ajenos a la voluntad, a la capacidad y al mérito del sujeto; "los contactos", "caerle bien al jefe", "el enchufe", "la imagen" del solicitante de trabajo, el hecho de poseer o acatar características que faciliten la consecución de los objetivos de reducir al máximo los costes salariales ${ }^{28}$ se conforman como los criterios operativos cara a la consecución del puesto de trabajo.

En algunos sectores, se reclama insistentemente la "concesión" de oportunidades individuales (que toman la forma de la concesión de una "gracia" y que, por lo tanto, están sometidas a la estructura del poder) como única forma de acceso posible a tan anhelado trabajo (que pasa a convertirse en un privilegio). El esfuerzo y la capacidad de los individuos no cuentan si no hay oportunidades para demostrarlos. Los cauces habilitados para conseguir las oportunidades de acceso (enviar currícula, fundamentalmente) y que no basculan en torno a la activación del capital social, escaso en estos colectivos, se encuentran cegados tanto por saturación y multiplicación de los requerimientos, como porque el canal (generalmente Internet) es reiteradamente instrumentalizado para obtener información de los solicitantes con fines publicitarios, fundamentalmente. De esta manera, la posibilidad de mostrar sus habilidades, así como su voluntad para esforzarse, se ve denegada por unos canales inoperantes e, incluso, ficticios. Tampoco acercarse a los lugares de trabajo (forma tradicional de búsqueda en una parte importante de estos sectores, especialmente en la construcción), parece servir como forma de mostrar experiencia, puesto que la saturación de personas en las mismas circunstancias ha conducido a que no tengan siquiera la oportunidad de la aproximación física a dichos espacios laborales (la obra, el comercio o el almacén, por ejemplo). Su experiencia laboral, ese gran activo operativo en un pasado mitificado, se desvanece hasta llegar a la máxima devaluación ${ }^{29}$.

${ }^{28}$ Especialmente se hace referencia al acatamiento de condiciones de trabajo que rayan la esclavitud (según sus propias palabras). Es esta degradación del mercado de trabajo, que hace referencia a "jornales" miserables, ausencia de contratos y jornadas sobrecargadas e interminables, lo que parece estar en la base de la percibida mayor elegibilidad de la población inmigrante, y uno de los argumentos que se esgrimen como justificativos de la rivalidad que en importantes sectores - especialmente en el caso de los obreros jóvenes y maduros, así como en el sector de clase media baja-, se despliega contra este colectivo.

29 “¿Dónde queda la experiencia y toda la ... mierda que tenemos?”(GD2). 
A pesar del debilitamiento del mito, se asiste a una fundamental insistencia ambivalente en la necesidad de esforzarse ${ }^{30}$, esfuerzo que la mayor parte de las veces se concreta en actividades formativas (para ellos y especialmente en la proyección del futuro de los hijos). Se desarrolla un proceso de construcción de una amplia desconfianza en relación a sus propias capacidades y "méritos" para poder acceder a un mercado de trabajo hiper-exigente, en un contexto de competencia desmesurada por el acceso a puestos de trabajo escasos - para los que, se percibe, se reclama sobre-cualificación-. En este sentido, la formación (y más concretamente las credenciales que la certifican) y la educación formal se conforman como el objetivo básico, única lejana posibilidad — pensada sin demasiada confianza—, y como la base necesaria para ubicarse en posición de superar la situación presente y/o futura ${ }^{31}$. Son los jóvenes obreros descualificados, los que más obsesivamente articulan su discurso en torno a una mitificación desmesurada de la rentabilidad de los procesos formativos. En muchos de estos casos, conscientes de la carencia de cualquier tipo de elemento distintivo que les haga valorables en el mercado de trabajo, se produce una búsqueda obsesiva de espacios formativos que les permita acceder a los mismos puestos que en momentos previos a la crisis desempeñaban. La formación se muestra para este colectivo como la única posibilidad de engarce en un mercado de trabajo en contracción y del cual han sido desplazados.

Por el contrario, quienes sí poseen credenciales, sobrada formación y acumulada experiencia (característica común en los sectores de profesionales), denuncian su inoperancia en un contexto caracterizado por la ausencia de puestos de trabajo que ocupar y por la eficacia de formas alternativas, relacionadas con la posesión de capital social ("los contactos") como vía privilegiada de acceso.

Por otra parte, la crisis meritocrática se proyecta también sobre los bienes, servicios y prestaciones que oferta potencialmente el Estado y a los cuales el colectivo de «nuevos pobres» en términos generales, considera que no accede, y no porque no se lo merezca. Algunos de estos recursos son percibidos como simples "limosnas" que no responden en ninguna medida a los criterios del mérito y el esfuerzo ${ }^{32}$.

${ }^{30}$ Discurso del esfuerzo y del sacrificio plenamente operativo, incluso en estos colectivos arrollados por la crisis.

${ }^{31}$ Habría que señalar la excepción que constituye el grupo de obreros adultos, así como el de las mujeres con responsabilidades familiares, que apenas apuntan hacia el espacio de la formación como horizonte factible o siquiera imaginable.

${ }^{32}$ Es en relación con el acceso a los escasos recursos de protección provistos por el Estado, especialmente en lo relacionado con las becas, espacios formativos, y en alguno de los casos el acceso a ayudas, donde se despliega, especialmente en el subsector de los sujetos procedentes de clase media baja y los obreros, un discurso que exacerba la rivalidad con sectores más tradicionalmente intervenidos (minorías étnicas, población inmigrante, mujeres maltratadas, etc.) 
El colapso de la sociedad de las clases medias: la creciente polarización del modelo de estructura social y la pobreza no nombrada

El convencimiento de que se avanzaba hacia una sociedad en la que las clases sociales habían llegado a su disolución y que, cada vez, se ampliaba en mayor medida el volumen de las clases medias ${ }^{33}$, reconociéndose amplias capas de la población como pertenecientes, de una forma u otra, a dicho conglomerado, parece haber llegado a su fin, por lo menos en este sector social.

El espejismo de la pertenencia a esa imaginada clase media capaz de aglutinar un sentido de pertenencia a este amplio grupo social, venía a funcionar como marco de integración social básico. Como señala Ramos Mejía (2011: 7) "el imaginario de pertenencia a dicha clase simbolizaba la posibilidad de ascenso social, la garantía de que el trabajo y su compensación mantenían un vínculo, la posesión de ciertos derechos, la garantía de ciertos atributos educativos y culturales, los distinguía tanto de las clases dominantes como de los ubicados en lo más bajo de la estructura social". En el caso español la multiplicación del empleo derivado del sector de la construcción, así como el desarrollo del sector de los servicios y el empleo creciente en el sector público (con una administración en expansión en los años 80 y 90) posibilitó el acceso a empleos, muchos de ellos precarios (pero en situación de relativa abundancia) y muchos otros permanentes, acompañados de prestaciones y servicios, así como facilidades de crédito, de tal forma que muchos trabajadores terminaron por sentirse parte de la clase media (como encarnación de ese deseado progreso).

Frente a esta sociedad de clases medias, en términos generales la percepción de la estratificación actual remite a una miradas dualistas de la sociedad ("ellos" —los ricos y poderosos - frente a "nosotros" - el pueblo, los trabajadores-) en una concepción dicotómica de la sociedad, polarizada, donde unos lo tienen todo y otros carecen de todo; división entre ricos (unos pocos) y los que se empobrecen (en el sentido de empobrecimiento generalizado del conjunto de la población); e, incluso en el segmento desfavorecido, entre unos que trabajan hasta la extenuación —en ocasiones sin remuneración, en el contexto de empresas en crisis - mientras muchos otros permanecen sin trabajo. En esta mirada polarizada se habla de la vida de los ricos (categorizados con un nivel máximo de abstracción), de lo que se permiten y derrochan, en términos de inmoralidad, pero también de irresponsabilidad. Mien-

${ }^{33}$ El concepto de clase media, a pesar de su enorme éxito en las sociedades contemporáneas, adolece de una fuerte indeterminación. En términos generales, el concepto asienta su éxito más que en una consideración de sus definiciones en términos de posicionamiento en la estructura productiva - y social—, en sus relaciones con una situación de rasgos comunes vinculados al acceso al consumo. Minujín y Anguita (2004) señalan que, en general, la gente entiende que la clase media viene a ser un gran espacio de población que no es ni muy pobre, ni muy rica y que cuenta con algo de capital económico o cultural y/o social (utilizando la terminología de Bourdieu). En España, está atribución a la clase media, está muy vinculada al acceso a la vivienda en propiedad. 
tras tanto, "el pobre", "el currito", "los trabajadores", "el pueblo" (muchas son las acepciones que surgen), son percibidos como los que realmente generan crecimiento, desarrollan la economía y distribuyen el gasto a través del consumo en los pequeños negocios.

Así, a aquellos que se engloba en la clase poderosa (de rasgos muy monolíticos, claramente minoritaria y frecuentemente asociada de forma prioritaria a los políticos y no tanto a la clase "capitalista"), además de la inmoralidad, se les atribuye la incapacidad de sacar adelante al país de la crisis, porque no son ellos los que movilizan el dinero en el mercado interior, sino que lo acumulan o gastan la mayor parte de las veces fuera del país. De forma sorprendente, el capital multinacional especialmente el financiero (bancos y multinacionales en su vocabulario) - apenas circulan en los discursos (si exceptuamos un segmento de los obreros adultos y el de jóvenes con estudios universitarios), y cuando lo hacen es siempre en un segundo plano. De la crítica más o menos aséptica a los bancos, se pasa rápidamente a una crítica virulenta y colérica a los políticos, a quienes además del lucro, se asigna el papel de la traición, la mentira y el engaño.

En términos generales, no hay una mirada global del proceso de fragmentación y de re-estructuración de la sociedad, sino una mirada local (nacional) que clasifica en pobres y ricos incluyendo en este segundo grupo a políticos - fundamentalmentey bancos (como entidades y no tanto como sujetos actuantes, "los banqueros" o "los directivos"). A estos grupos se les denuncia básicamente en términos de desigualdad de rentas, no se cuestiona su capacidad de decidir, de establecer modelos de desarrollo, de definir las estrategias de política económica, o su poder a la hora de imponer determinada visión de la sociedad. Aparte estarían los medios de comunicación que no se conciben como grupos económicos, ni de poder, sino como entes subordinados a dicho poder político y económico, que les defienden, que ocultan el malestar, la protesta y las desigualdades. Es decir, los ubican en la esfera de la producción de legitimidades, pero no del poder económico y político directo.

Solo en alguno de los sectores (el de los jóvenes cualificados y el de los profesionales) aparece, y de forma más central, una mirada hacia los procesos de globalización y la preminencia del capital financiero y multinacional, del que se llega a enfatizar que opera bajo la exclusiva lógica del beneficio económico y la rentabilidad, desentendiéndose absolutamente de otro tipo de criterios de carácter social.

En el caso de los jóvenes descualificados, a la brecha radical enunciada entre los pobres y los ricos, se superpone una fractura que es percibida como generadora de nuevos focos de conflictividad; es la fractura entre aquellos que trabajan y los que $n^{34}$. A este espacio conflictivo, se suma, además, la brecha generacional que se

${ }^{34}$ En el caso de estos jóvenes descualificados perciben su situación de desempleo como un problema mayoritario entre sus conocidos y amigos, apuntándose la anecdótica existencia de casos que sí han accedido al empleo, sujetos a los que atribuyen ciertas cualidades 
percibe como divisoria entre aquellos que pudieron acceder al trabajo estable, y a los beneficios del incipiente Estado del Bienestar tras la transición y, por otra parte, los jóvenes que, sin trabajo y sin estabilidad, están abocados a vivir del colchón familiar que, gracias a sus ahorros, pudieron capitalizar las generaciones de sus padres. También emergen espacios de competencia entre los jóvenes maduros y los más jóvenes, percibiéndose a estos segundos como privilegiados por las políticas públicas de fomento del empleo entre los jóvenes, de las cuales ellos quedan excluidos $^{35}$. Frente a ellos, aducen madurez y experiencia para hacerse valer en este proceso competitivo por puestos laborales muy escasos. Asimismo, surge la línea de competencia entre varones y mujeres, en un contexto en el que éstas continúan disponiendo de algunos espacios muy precarios donde desarrollar actividades laborales remuneradas relacionadas especialmente con el trabajo doméstico y los cuidados; actividades que en muchas ocasiones vienen a constituir la principal fuente de ingresos en el hogar, generando en ocasiones espacios de conflictividad. Finalmente, otra brecha que emerge como fundamental es la que se establece entre inmigrantes y población nacional. Esta fractura surge de forma muy virulenta en el caso de los obreros maduros como criterio percibido de estructuración fundamen$\mathrm{tal}^{36}$.

Pero todas estas fracturas que se discuten y emergen con especial profundidad en subsectores concretos, se subordinan a la que aparece como fundamental: la de los ricos y los que no lo son. Esta hiper-fragmentación y complejización de la estructura social en la que se fomentan los enfrentamientos y las diferencias, frente a la

excepcionales ("una amiga que es muy lista" GD6), y con los cuales mantienen espacios de conflictividad ("te dicen que te están manteniendo" GD6).

${ }^{35}$ Como ellos señalan, no se les ha dejado convertirse en adultos, pero ya son expulsados de la categoría de jóvenes.

${ }^{36}$ En un claro despliegue de un discurso populista y xenófobo, desde este segmento de los «nuevos pobres», "el pueblo" en el cual se integran, es concebido de forma uniforme frente a las élites y frente a un otro (extranjero fundamentalmente) protegido, privilegiado y mimado por dichas élites políticas y económicas. Se desarrolla un discurso fuertemente estereotipado de rechazo de lo que consideran sus privilegios: ayudas, trabajo y acceso a los servicios, privilegios que, perciben, han tenido como consecuencia la quiebra del mercado de trabajo y de los derechos laborales. Se critica el monopolio de "los chinos" en el comercio, los privilegios de "los latinos" y su resistencia a la adaptación; se fantasea, también, en torno a la concreción de los privilegios: "no pagan impuestos", "se unen en grupos", "no contratan a españoles", "se ríen de nosotros", "no se adaptan", "revientan los mercados" (de mercancías y de fuerza de trabajo), "sacan dinero de España y nos empobrecen" (en relación a las divisas), etc. En este contexto, se desarrolla una amplitud de apuestas vinculadas a la reivindicación de un cierto nacionalismo español en el que se reclama la protección de lo propio, de lo español, lo que por minoritario - en una clara distorsión de la realidad-, y como consecuencia del abandono, debe ser protegido. El problema de la crisis "estructural" se transforma así en un problema de flujos de inmigrantes, y se naturaliza el rechazo hacia el inmigrante como "defensa del ecosistema"(GD2). 
toma de conciencia de los intereses colectivos, ha sido uno de los grandes éxitos de los argumentos legitimadores del modelo capitalista, que parece comienza a resquebrajarse, aunque encuentra una importante resistencia entre algunos segmentos de «la nueva pobreza».

Finalmente, aparecen también las imágenes de la pobreza como riesgo próximo donde, por el momento, no se ven involucrados. Curiosamente ninguna de las personas que han entrado a formar parte del trabajo de campo se auto-concibe abiertamente como incluida en el grupo de pobres, (a pesar de que objetivamente y según los indicadores, así lo sean, y de que buena parte de ellos y ellas reconozcan abiertamente que de no ser ayudados por sus familias "estarían en la calle"), más allá de los discursos retóricos y las frases hechas que remiten a la contraposición polarizada rico-pobre, o de una consideración fugaz en la que se incluye el vocablo en frases tópicas ${ }^{37}$. Sí se habla de necesidad, de privaciones concretas vinculadas a su vivencia, pero no de pobreza. En este sentido, se constata la validez del diagnóstico formulado por Wacquant (2007) según el cual, el lugar de la pobreza, definida como carencia, como ausencia, y frecuentemente estigmatizada, difícilmente se constituye como lugar social de identidad posible, dificultando de esta manera la toma de conciencia de la propia situación y frenando las posibilidades de la emergencia de posicionamientos colectivos.

Parece permanecer en el imaginario la imagen tradicional de la pobreza como equivalente a miseria, pobreza evidente, pobreza de solemnidad, pública y que se presenta abiertamente en las calles. Es el espacio de la pobreza extrema, antes restringido a espacios muy minoritarios, y que paulatinamente comienzan a ver aproximarse con verdadero "horror"; es el horror a una pobreza antes mantenida bien distante y debidamente categorizada y "culpabilizada" a partir de una concreción de características básicamente de carácter individual, contempladas en términos de déficits morales o de capacidades. En este sentido, a pesar de la amenaza en ciernes, ellos no se ven involucrados en esa pobreza tradicional que se restringe a los casos extremos, que representan y concretan, de manera casi unívoca en "aquellos que rebuscan en la basura" o "aquellos que están en la calle".

Así, esa pobreza no nombrada, esa pobreza moderna, sería una de carácter privado, que se sufre en la intimidad, que aqueja a "la gente normal", que no invade la calle y no es extrema, que se ve (auto)censurada y disimulada, y que consigue paliarse solo gracias a la ayuda de familiares, cuando esto es posible. Solo muy ocasionalmente se explicita el uso de servicios públicos o privados especialmente habilitados para atender situaciones de pobreza, servicios que en muchas ocasiones

${ }^{37}$ Cuando la dinámica del grupo o de la entrevista empuja hacia un cierto posicionamiento en la estructura social (una cierta presión indirecta al auto-posicionamiento) se produce frecuentemente una ampliación por elevación, de forma que se convierte en pobres a todos los parados, o incluso en el contexto actual a toda la clase trabajadora, de manera que se termina por equiparar pobreza con las clases populares. 
parecen estar ausentes del abanico de posibilidades. En buena parte de los grupos y entrevistas surge reiteradamente el tema de la vergüenza de pedir ayuda, de la humillación que supone y de las estrategias que se despliegan para evitar demandarla $\mathrm{o}$, incluso, hacer saber siquiera la situación de privación que se padece (en ocasiones, incluso, a los propios familiares). Es así, una pobreza que desde su invisibilidad social, carece de fuerza de presión y se muestra incapaz para potenciar la denuncia.

\section{El desplazamiento práctico-táctico del lugar del consumo}

En el espacio social de la «nueva pobreza», las prácticas de consumo pierden su lugar estratégico como espacio de integración social y posicionamiento en el sistema de estratificación, en un desplazamiento forzado y profundo hacia pautas de subconsumo y modelos de privación. Se replantea el propio espacio del consumo, emergiendo debates y reflexiones sobre el mismo que han estado ausentes en amplias capas de la población (las generaciones de edades intermedias y especialmente los más jóvenes) durante los últimos treinta años. En un contexto en el que la supervivencia misma está puesta en cuestión, se vuelve a los discursos más básicos focalizados sobre el valor de uso de los bienes de consumo. Se constata cómo la crisis económica ha supuesto un cambio de hábitos en los diferentes aspectos de la vida, que incluyen enormes restricciones en los consumos que han derivado en formas y normas de subconsumo.

Se desarrollan amplias discusiones sobre lo que constituye el eje de las necesidades y aquello que es superfluo y/o capricho. Se imaginan las formas posibles de incrementar y alargar el valor de uso de los productos, y se critican los aspectos relacionados con el valor de cambio y/o el valor simbólico diferencial de las mercancías (excepto todo aquello que se vincula con el consumo de integración normalizada, asentado en los consumos básicos y en un mínimo ocio relacional - de manera fundamental orientado hacia los hijos-).

Al mismo tiempo, un sector importante de los nuevos pobres construye una crítica al proceso de renovación incesante de los productos, que caracterizaría buena parte de las pautas de consumo de los sujetos particulares, incluso, de sus propios comportamientos en un pasado inmediato. En el debate sobre lo que se considera consumo legítimo o ilegítimo - totalmente ausente de los principales debates tan solo unos años atrás-, es donde se localiza una parte importante de los enfrentamientos discursivos en el seno de los grupos. Se cuestiona qué es la necesidad frente al "capricho", qué es el consumo asentado en «las posibilidades», por encima de las posibilidades, qué es un consumo basado en el lujo, de forma que se desenvuelve un aparente consenso en torno al rechazo del consumo ostentoso y de la lógica consumista ligada al deseo y al placer, una defensa de la garantía de unos mínimos de supervivencia y una fuerte polarización en torno a lo que constituye "consumir según las posibilidades", que generalmente se condensa añadiendo al consumo de supervivencia, aquel que viene a garantizar la integración normalizada en las redes de interacción social. 
Hay una defensa de los marcos educativos racionalizadores en relación con el consumo, haciendo hincapié en los beneficios de educar en la escasez, si bien se pone de relieve cómo el gran problema, más allá de la educación en el seno de la familia, lo constituye la presión del entorno social, según el cual, quien no puede acceder a unos estándares básicos de consumo queda señalado, estigmatizado $\mathrm{y}$, posiblemente, relegado socialmente (desplazamiento que es vivido de forma especialmente angustiosa en el caso de los hijos). No obstante, en el conjunto de los grupos, pero de manera mucho más relevante en el caso de aquellos que han ocupado posiciones más acomodadas y emprendedoras, este proceso de reubicación descendente y desalineamiento está siendo especialmente doloroso en lo que se relaciona con el proceso de resocialiación en la privación por parte de los niños y adolescentes. El obligado paso - y la adaptación - al principio de realidad, cuando las generaciones de descendientes estaban instaladas en el principio de placer, muestra ser profundamente doloroso. Se desarrolla toda una polémica en torno a la jerarquía de las necesidades y lo que implica volver a la mera satisfacción de la pura supervivencia, a la renuncia al consumo más allá de ésta, que emerge asociada a la potente metáfora de "la vuelta a las cavernas" (GD3) o a "la esclavitud" (GD2).

Si bien hay un cierto acuerdo en la censura moral del "vivir por encima de las posibilidades" - $\tan$ insistentemente preconizada en los medios y en los discursos políticos-, no hay ningún consenso en relación a la consideración del consumo adecuado a las posibilidades, esto es, en sus propias palabras, el consumo limitado y adecuado "al poder adquisitivo". En relación con este posicionamiento exculpatorio por parte de los que se sienten acusados de exceso de consumo, se localizan también las palabras reconfortantes y la complicidad de sectores que restan poder demonizador a esos "excesos", justificando su adaptación a las posibilidades muchas veces muy limitadas - y al poder adquisitivo del grupo. Sin embargo, el sector más "puritano" acusador y enjuiciador de los excesos de consumo —en un despliegue mimético del discurso mediático de carácter culpabilizador-participa de la crítica a la incapacidad de previsión - siempre apuntando al consumo de los más vulnerables-, a la renuncia al ahorro y al chantaje consumista de los hijos, a la incapacidad de diferir satisfacciones inmediatas, así como a la generación de falsas necesidades.

El desplazamiento de la centralidad de ese consumo de masas (construido, en gran medida, a través del endeudamiento) que está en la base de la gran transformación cultural de la modernidad, constituye un elemento crucial en el debilitamiento del ideal del consumo basado en el puro deseo. Se debilita, en este sentido, una forma de dominación asentada en la participación consentida en las formas de apropiación del excedente. A pesar de ello, es este un desplazamiento forzado que se sitúa en el nivel de lo material y no en el cambio de mentalidades. En el fondo de los debates, se puede localizar una crítica de corte muy superficial al consumo que, pese al rechazo formal, sigue siendo el eje articulador de las aspiraciones, si bien se ve frustrado en las prácticas, como consecuencia de la carencia de ingresos, de forma que se vive como adaptación lo que de suyo es la necesidad de reprimir constantemente el deseo (estrategia de clara racionalización), volviendo así a mode- 
los de vida que han caracterizado a generaciones precedentes o a grupos sociales, socializados en el subconsumo, cuyos hábitos de vida y especialmente de vivienda, permiten una mayor austeridad.

Dicha contradicción entre prácticas limitativas y expectativas, genera un malestar creciente que, no obstante, no se articula argumentativamente, sino que emerge en forma de metáforas o lapsus. Así el ideal del consumo más allá del nivel de simple supervivencia sigue operando como factor de aspiración, si bien es materialmente negado por la situación objetivamente vivida. En buena parte de los casos se produce una recuperación (acompañada de valoraciones positivas) de modelos de consumo antes rechazados o no admitidos o considerados, como el trueque, la reutilización, la demanda a los próximos de lo que no necesitan, o el comercio de segunda mano. En este contexto, necesariamente crítico con el consumo ostentoso, se recupera la valoración retórica, y resignadamente positiva, del valor de uso de productos y servicios, si bien la aspiración y añoranza del consumo consigue imponerse por encima de las prácticas y de la retórica crítica. Se han dejado de consumir símbolos para volver al valor de uso y la maximización de utilidad, consecuencia del tantas veces repetido "apretarse el cinturón", pero en el nivel de las aspiraciones pervive el anhelo de la vuelta al modelo del consumo simbólico tamizado por una retórica crítica que, sin duda, hace mella en el discurso legitimador.

En el caso concreto de la población inmigrante, el espejismo del consumo que se había venido haciendo concreto en la percepción de Occidente como "paraíso"38, es tempranamente desmitificado en el momento mismo de la llegada al contexto español, aunque dicho espejismo mantiene su capacidad de conservar las ataduras con pequeños consumos que iban posibilitando el acceso a una integración pausada. Ante la actual situación de privación es, precisamente este grupo social, el mejor adaptado -material y simbólicamente- al subconsumo.

En general, se desarrollan posiciones discursivas que se muestran distanciadas de las prácticas del consumo efectivo, aunque en buena medida siguen parcialmente operativas una parte de las prácticas sociales vinculadas a un consumo imposible ("merodear los centros comerciales" - GD1, GD6-) como actividad de ocio, especialmente en el caso de los más jóvenes. Sin embargo, en el caso de los más mayores, se produce el fenómeno contrario que se traduce en una huida de los espacios públicos, a los que se vincula, exclusivamente, con el acceso al consumo, y que recuerdan amargamente su imposible materialización. Este alejamiento de los espacios públicos contribuye, en buena medida, a acentuar los procesos de aislanto que reiteradamente van emergiendo.

De cara a garantizar la supervivencia, la privación es vivida de forma menos angustiosa en el caso de los jóvenes que han regresado al hogar paterno-materno, en tanto en cuanto, las necesidades básicas las mantienen allí cubiertas y no cuentan, la

${ }^{38}$ Así es abiertamente semantizado en el caso de estas personas en la narración del seductor sueño que antecede al proceso migratorio (GD4, E2, E3). 
mayor parte de las veces, con personas dependientes a su cargo. Pero a pesar de ubicarse en una posición menos angustiosa en lo inmediato material, estos jóvenes se han socializado y han centrado su identidad en torno a los espacios de consumo (fomentado por una socialización en una amplia disponibilidad de bienes de consumo ociosos ${ }^{39}$, por un acceso precoz a recursos económicos - exiguos-- facilitado por una inserción muy temprana - y precaria - al mercado de trabajo ${ }^{40}$, sin olvidar la generalización de los medios de pago aplazado). En este contexto, estos jóvenes señalan no estar preparados para afrontar la privación de esos consumos (que son básicamente de carácter relacional) incrustados en formas de vida que son básicamente presentistas. Al mismo tiempo, en este colectivo se desarrolla una amplia crítica a los progenitores (y todo el entorno social adulto cómplice) a quienes se reprueba no haberles preparado para vivir sin consumir. Es, precisamente, en este colectivo donde se concentra, en buena medida, una incipiente agresividad verbalmente manifestada, y donde se puede entrever el desarrollo posible de espacios de revueltas anti-normativas y violentas. En este sentido, la rabia explicitada, junto con una sensación de impotencia y desesperanza, podría constituir un caldo de cultivo especialmente apropiado para la concreción de explosiones de malestar descontroladas, que en el momento actual parecen restringirse al ámbito de la fantasía discursiva.

\section{Crítica al funcionamiento del sistema democrático de partidos}

La percepción del sometimiento de las políticas nacionales a los dictados de la Banca, del capital multinacional y de los organismos internacionales, hace que uno de los elementos claves de la construcción legitimada de los estados nacionales, el ideal de la soberanía nacional, se desmorone. Aquí se inscribe la crítica a la subordinación de los gobiernos y políticos profesionales, a intereses económicos de carácter supranacional $^{41}$, y a intereses económicos particularistas.

En un marco de fuerte crítica al bipartidismo como fórmula de gobierno, se acusa a la clase política de no actuar en representación; así los gobiernos y la clase política en su conjunto, se perciben como nepóticos, corruptos, ladrones y desconocedores de los problemas de una ciudadanía a la que desprecian, a la que vampirizan y de la cual se mofan, centrados en sus intereses particulares. La actividad política se percibe como vía de promoción personal, especialmente económica. Se observan estrechas vinculaciones entre políticos y capital financiero, cuya acción conjunta consideran "un circo" (GD1), es decir, una farsante actuación en la que

${ }^{39}$ Gracias a la subvención paterna - directa e indirecta- de los consumos (expresión del consumo vicario en términos de Veblen).

${ }^{40}$ Es el caso de los jóvenes que abandonaron precozmente el sistema educativo y accedieron a trabajos no cualificados.

${ }^{41}$ Intereses que se personalizan en buena medida en la figura de Merkel, reactualizándose, incluso, el fantasma de la Alemania fascista (E5). 
solo algunos se ríen, en un simulacro fallido de lo que deberían hacer (orientarse al bien común). A los bancos (y solo en algunos casos las multinacionales) le son atribuidas grandes dosis de poder, y se denuncia la total incapacidad y falta de voluntad de la clase política para frenarlos (y pedir responsabilidades), debido a su co-participación. Es más, se percibe que la clase política no solo no frena, sino que participa del expolio, arropándose los unos a los otros, de forma que no se trata de individualidades corruptas, sino de "sistemas mafiosos" (GT1), al tiempo que se les atribuye intentar manipular a la ciudadanía engañando continuamente con la complicidad de los medios de comunicación.

En este contexto, el rechazo con respecto a los representantes políticos es absoluto, no diferenciándose entre unos partidos y otros, entre unas ideologías y otras, de forma que el cuestionamiento del sistema democrático de partidos encuentra un caldo de cultivo especialmente propicio. La política se convierte en el espacio del interés particularista asentado en importantes cotas de engaño. La despolitización, así, se percibe como el espacio posible para la neutralidad ante un colectivo que se considera deshonesto en su conjunto. Se reclaman gestores y técnicos responsables y no políticos a los que se vincula indisolublemente con la defensa particularista de sus propios intereses. Así, se habla de la política como asunto sucio y corrupto.

Del Estado y sus instituciones no se espera nada y, en general, no se le reclama nada tampoco (más allá de que no sean corruptos y que controlen los flujos migratorios), de tal manera que se localiza un profundo divorcio entre las instituciones y, más concretamente, entre los políticos y la ciudadanía. En este divorcio no solo se apunta hacia una profunda diferencia de intereses, sino que se construye un abismo, una completa falta de comunicación, un muro que los separa, que los convierte en totalmente impermeables a las demandas y a las necesidades de una "calle" y un "pueblo" a los que ignoran.

Las protecciones de rentas procedentes del Estado (como prestaciones, subsidios y rentas activas y de inserción) están muy desdibujadas en cuanto a sus fundamentos, orígenes y procedimientos y son vividas más como dádivas disciplinantes o concesiones con contrapartida que como derechos ${ }^{42}$. Los servicios sociales están

${ }^{42}$ En los escasos casos en los que se habla de las ayudas de los servicios sociales siempre se refieren a los mismos en términos de graciabilidad "si nos lo dan", "si nos lo conceden", lo cual hace que no se reclame, ni se exija de la misma manera. En general, no se conciben como correlato de unos derechos. Aunque la ayuda sea el resultado de una valoración de expedientes, la percepción de la base objetiva se disuelve. Todos se perciben con la máxima necesidad, con lo que si se consigue, es cuestión de azar, o de la voluntad de la persona encargada del trámite burocrático. La denegación de las ayudas genera frustración pero no rebeldía (las ayudas se agradecen, las prestaciones se merecen). Esta percepción aumenta con la constatación del incremento de la presión sobre el sistema de ayudas. Además, los servicios sociales públicos actúan, muchas veces, como gestores, y son las ONG las que proporcionan directamente la ayuda, lo que redunda en un aumento de la percepción 
ausentes en la mayor parte de los discursos o aparecen, fundamentalmente, en su vertiente represora y censuradora. Su presencia emerge con un lugar más relevante especialmente en el discurso de la mujeres con responsabilidades familiares en las que los servicios sociales se muestran en su vertiente más disciplinaria y de objetivación del poder burocrático - en el sentido weberiano - y parece concretarse a través de profesionales insensibles a la necesidad que se percibe se parapetan detrás de los protocolos ${ }^{43}$. De esta forma, el Estado no es percibido en ningún caso como Estado providencia, y mucho menos como Estado protector, sino como Estado disciplinante y disfuncional desde una perspectiva burocrática. Al mismo tiempo, se desarrolla una mirada pesimista con respecto a los sujetos sociales, a los que se considera desprovistos de toda capacidad de influencia política, de todo potencial para exigir justicia, o forzar la aplicación de la ley, o en su caso, presionar para lograr cambiarla.

Por otra parte, el lenguaje de la indignación que se ha popularizado a través del movimiento 15-M y la huida de la consideración del debate político como aquel centrado unívocamente en la disputa entre los dos partidos mayoritarios, sus líderes y sus desplantes, ha comenzado a plantear que la concepción limitada del conflicto político -identificada con el enfrentamiento entre los partidos mayoritarios-, parece haberse quebrado profundamente ${ }^{44}$. Son precisamente los jóvenes cualificados, un sector de la clase media funcional y los profesionales, y un subsector de los obreros maduros, aquellos segmentos en los que se puede localizar una mayor proximidad, simpatía, e incluso participación, en las proclamas, idearios y movilizaciones planteadas por este movimiento, al tiempo que son los sectores en los que, en mayor medida, se maneja el lenguaje de los derechos, de la ciudadanía y la reivindicación de carácter político.

Este debilitamiento de la legitimidad del sistema de partidos, comienza a hacer mella — si bien, en términos generales, no pone en jaque - en el modelo de democracia representativa. Se cuestiona el modelo en lo discursivo, si bien no se plantea argumentativamente ningún tipo de alternativa posible. En términos generales, se critica y acusa principalmente a los dos principales partidos, a los que se considera

negativa del Estado (que burocratiza) mientras son las asociaciones las que finalmente aunque solo ocasionalmente - ayudan.

${ }^{43}$ En alguno de los casos se localizan también espacios de reconocimiento y de valoración positiva y aprecio a profesionales concretas a las que se atribuye la capacidad de entender sus problemas y de poner en marcha los recursos disponibles para ayudar a las familias, sujetos que escaparían a la lógica de la institución.

${ }^{44}$ No obstante, hay que señalar que también se localiza un importante sector dentro del conglomerado de «los nuevos pobres» que se ubican en una posición muy beligerante frente al 15-M (especialmente el grupo de clase media baja y un sector del grupo de obreros adultos), al que descalifican reiteradamente. También emerge un sector importante que permanece completamente ajeno a su desenvolvimiento (ausencia especialmente llamativa entre los jóvenes descualificados). 
responsables del rumbo errático que está tomando el país, y con ello, se cuestiona su validez representativa. Pero - exceptuando el sector más movilizado políticamente, constituido por parte de los jóvenes con mayor cualificación - no se duda del modelo de la representatividad y, en ningún caso, se manejan fórmulas alternativas. Es más, se produce un proceso de desplazamiento en el que la culpabilidad de la degradación democrática la tienen, en última instancia, los votantes por votar a los representantes que tan virulentamente critican. De esta manera, el problema no es del modelo de representatividad, sino de los votantes que han elegido políticos corruptos, abundando en la tendencia hacia la asunción de la responsabilidad individual y generalizada de los malestares.

El avance constante de las políticas de austeridad, el indulto por el blanqueo de capitales, el de condenados por delitos (e indultados por el consejo de ministros), y el pago de costas de la justicia (que aparecen reiteradamente mencionados en las entrevistas de la última fase) han terminado de exacerbar el descrédito de la esfera política, y de los políticos en particular.

\subsection{La responsabilización individual culpabilizadora: el pecado del consu- mo como re-edición del pecado original}

En la actualidad y en el espacio social que estamos analizando, a la mayor parte de las personas afectadas por la «nueva pobreza» no se les achaca — como se ha hecho tradicionalmente desde posiciones moralizantes - patologías de desintegración o ausencia de voluntad de integración. Nos encontramos ante enormes volúmenes de lo que tradicionalmente venían a ser considerados "pobres dignos", colectivo que también incluye a trabajadores pobres, deseosos de integrarse socialmente, pero sin posibilidad de hacerlo de manera efectiva.

En este contexto, los procesos de atribución de responsabilidades con respecto a la situación actual de carencia de empleo y privación económica, pasan en primer lugar, por una auto-culpabilización generalizada de los sujetos acerca de la situación de crisis económica, y como correlato, de su propia situación de pobreza. En sus comportamientos previos, atravesados por la irracionalidad y la falta de previsión, radicaría la responsabilidad respecto de su situación actual.

Frecuentemente, y de forma muy especial en alguno de nuestros grupos (como por ejemplo entre los jóvenes descualificados y en una fracción del sector inmigrante), dicha socialización de la responsabilidad y de la culpabilización se ve reforzada por una atribución de carencias y falta de habilidades que obstaculizan su reintegración en la sociedad y en el mercado de trabajo. Es por ello, que su inserción se percibe condicionada a una asunción de la auto-responsabilidad sobre sus procesos formativos, a la búsqueda y creación de nichos de trabajo en el nuevo contexto de escasez e imposibilidad de que el Estado se haga cargo de dichos espacios de "reenganche".

Cabe destacar la insistente emergencia de la dimensión moral, fundamentalmente inscrita en términos individuales, de su situación de desempleo, subempleo y privación. Esta responsabilización e imágenes del origen de la crisis actual se desarrollan de manera muy similar a la narración mítica de la expulsión del paraíso. 
Los bancos emergen en los discursos metaforizados en la figura del "demonio" o "serpiente" tentadora ${ }^{45}$ frente a unos sujetos débiles, seducidos, que, individualmente ceden a "la tentación", provocando la ira de los dioses. Las fuerzas desencadenantes de su actual situación de privación pasan a situarse así en el espacio de las consecuencias - involuntarias - desencadenadas por su propio "pecado". Aparece, insistentemente, la culpabilización focalizada hacia el crédito fácil a la población en general aunque de manera muy especial a los más vulnerables, y como exponente tópico, a los inmigrantes.

Uno de los principales elementos que reiteradamente aparece en los discursos es la actualización del sencillo y eficaz eslogan, tan aireado por los medios de comunicación y por los discursos políticos, de "hemos vivido por encima de nuestras posibilidades", vinculándolo al "derroche" a través del crédito. Así, este proceso se percibe como la base de todos los males actuales, sin aparecer en ningún momento la diferente accesibilidad que los diversos grupos sociales han tenido al proceso de endeudamiento. De hecho, solo una pequeña parte de los sujetos señala haber recurrido a dicho sobre-endeudamiento ${ }^{46}$, aunque el uso retórico del "hemos" se generaliza a la mayor parte de los sujetos considerados. En ningún caso se articula una reflexión sobre cómo ese endeudamiento (más presente en otros colectivos que en estos sectores previamente precarizados), asociado al proceso de financiarización de la economía, ha contribuido de manera fundamental a engrosar tremendamente los beneficios de bancos, constructoras, compañías de seguros y, en general, todo el sector económico que se ha desarrollado a partir, precisamente, de esos comportamientos que ahora se critican. Tampoco se hace una reflexión de cómo gracias a estos procesos de endeudamiento ha sido posible desarrollar las políticas de contención salarial (otra de las importantes causas del endeudamiento de las familias Colectivo Ioé, 2012: 5-), así como fomentar el consumo y los beneficios empresariales. Por otra parte, tampoco se tiene en cuenta que una parte importante de los ingresos familiares, así como de la deuda que algunos hogares han contraído, se ha orientado a financiar recursos y servicios generados como consecuencia de la deficiente extensión y consolidación del Estado del Bienestar en nuestro país durante la fase de crecimiento. Así, los hogares se han visto incorporados a una fuerte dinámica de gasto en el acceso a determinados servicios (guarderías, actividades educativas complementarias, servicios de atención y cuidado, servicios educativos y sanitarios), pero de forma muy especial, en relación a la adquisición de vivienda a unos precios desorbitados (Aragón y otros, 2012). Todos estos argumentos están básicamente ausentes del discurso de la población considerada.

${ }^{45}$ Materializándose el símbolo de la tentación en la tarjeta de crédito o el crédito fácil.

${ }^{46}$ Según un indicador de endeudamiento elaborado por Belzunegui y Pastor (2012: 55) a partir de la ECV, del total de la población española, un 76,3\% podría clasificarse en situación de endeudamiento nulo, un $6,7 \%$ en situación de endeudamiento moderado, un $8,6 \%$ de endeudamiento severo y un $8,4 \%$ de alto endeudamiento. 
En la mayoría de los discursos articulados en nuestros grupos, al capital financiero y a los políticos - especialmente a estos segundos - se les atribuye la responsabilidad de generar falsas expectativas e invitar al sobreconsumo en base al fomento y la facilitación de los créditos baratos para así garantizar su rentabilidad, mientras que son los ciudadanos y grupos los responsables últimos de ceder ante "la tentación", y tomar la decisión de endeudarse. No aparece en ningún caso el problema del endeudamiento de las empresas inmobiliarias, ni de la colaboración en ese proceso tanto del capital financiero como de la clase política. Los bancos (que sistemáticamente se señala ofrecían mucho más de aquello que se reclamaba financiar) son los que encarnan la tentación (el demonio). Pero, finalmente, el responsable del "pecado" es el ser tentado, el sujeto irracional y moralmente débil que cedió ante una tentación que resultó irresistible, generando de esta forma, la culpabilidad individualizada y el consiguiente inmovilismo.

Estas son las principales metáforas de carácter cuasi-bíblico que se usan al referirse a la "expulsión del paraíso del consumo", tras haber sido tentados por el hedonismo y la emulación. Los responsables son los sujetos pecadores que deben redimirse (a través del esfuerzo y el regreso a la moral puritana, esto es, al ahorro, al "ajustarse el cinturón" y a asumir las políticas de austeridad como contrapunto de sus excesos), aunque en un contexto que ya no será el paraíso sino el desierto, la carencia y la escasez.

La auto-responsabilidad sobre lo que se está viviendo se lleva, incluso, al terreno del carácter nacional, de haber soñado que España ingresaba en el club de los países ricos cuando el país no reunía los requisitos para ello, y cuando el "carácter nacional" nos lo impediría. Así, se apunta cómo la falta de civismo y honestidad generalizada que caracteriza a la sociedad española, la ocultación, el aprovecharse de las situaciones, la mentira y el engaño (frente a la legalidad y la honestidad), la irracionalidad y la falta de reflexión, serían déficits morales de los que participan conjuntamente todos los españoles, por lo que todos vendrían a ser culpables.

También se presenta la auto-responsabilización sobre lo que se consideran opciones de venta de mano de obra equivocadas u opciones de modelo productivo en relación a los cuales se asume una parte de la responsabilidad colectiva. Se señala que los jóvenes y parte de los adultos se han equivocado al "optar" mayoritariamente por trabajar por el sector de la construcción ("nos hemos tirado toda la gente joven, a la construcción, porque es lo que daba dinero. Pero claro"; "Hemos hecho una locura. Hemos construido para nada" -E6-).

Este proceso de auto-responsabilización, de socialización de la culpabilidad y de la individualización de los déficits, tiene un eficaz efecto a la hora de desactivar la capacidad de crítica de los sectores englobados en el conglomerado de la «nueva pobreza».

Desde 2011 (momento en el que se desarrolló la primera parte del trabajo de campo) hasta el final de 2012 se puede percibir que se va produciendo una cierta mella en este argumento que hace un año presentaba una gran contundencia. Incluso en los sectores más imbuidos de esta lógica de la auto-responsabilización se comienza a hablar de que no es que se haya vivido por encima de las posibilidades en 
general, sino que no ha habido previsión, que no se ha ahorrado, que se han gastado todos los excedentes que sobraban de los gastos cotidianos. Emerge, especialmente en los sectores con mayores cualificaciones y mayor capital cultural un significativo desplazamiento desde el "hemos vivido", al "nos han hecho vivir" en una ilusión, en una ficción. Incluso, en los propios grupos y en las entrevistas, se puede observar un cierto dinamismo en el que desde una ubicación prioritaria en la responsabilidad fundamental de los sujetos "consumistas" se va virando en el propio desarrollo del discurso de los sujetos, hacia posiciones matizadas, mas reflexivas y, en algunos casos, encolerizadas en las que la responsabilidad se escora en mayor medida hacia determinados agentes protagonistas que fomentaron el desarrollo del modelo especulativo y que sí vivieron - en este caso ellos sí - por encima de sus posibilidades. De hecho, llega a derivarse una curiosa paradoja, que es la de denunciar que de hecho son ellos mismos "los supervivientes", los que están actualmente "sobreviviendo" por encima de sus posibilidades, ya que, o bien estas se reducen básicamente a la nada, o los salarios en el momento que viven no son suficientes para poder cubrir las necesidades que se definen como básicas. Ni siquiera los comportamientos ahorrativos en un pasado (que fueron frecuentes en estos sectores sociales), ni siquiera el hecho de poder acceder a un puesto de trabajo, les sirven para garantizar su supervivencia actual (en este sentido, claramente, la gente sí está sobreviviendo por encima de sus minúsculas posibilidades, gracias a la ayuda de los familiares o a recursos suplementarios que permiten un pequeño complemento).

\subsection{La política de las apariencias y la autocensura del malestar}

El conjunto de elementos de malestar y crisis de legitimidad que se han ido comentando se suman al nuclear malestar material que supone el empobrecimiento en un contexto en el que, además, mostrar o evidenciar frustración o angustia es percibido como manera de incrementarlos. Los sujetos englobados en estas categorías autocensuran la manifestación de su malestar puesto que consideran que ello incide en un empeoramiento de su situación, en una percepción más global de malestares que hunde, así como en un alejamiento de los próximos, desarrollándose de esta manera toda una política de las apariencias en la que la queja es causa y no consecuencia de los profundos desazones ${ }^{47}$. En esta línea censuradora se desarrollan argumentos que plantean la evitación de la socialización del malestar, para sortear el contagio. Indirectamente parece apuntarse al hecho de que el problema de la privación y la carencia radica en uno mismo y se vendría a superar desde dentro, de forma que prácticamente viene a ser una "enfermedad del yo", más que un problema de la sociedad.

${ }^{47}$ Este tipo de enmascaramiento del malestar como fuente censuradora de la protesta, se está manifestando muy productivo a nivel de las estrategias comunicacionales desplegadas por el poder político en sus diversas manifestaciones. 
Otra de las características constantemente presente es el continuo debate entre la imposibilidad de tener una mirada optimista y positiva y, sin embargo, la necesidad imperiosa de ello. Constantemente y en relación con la multiplicidad de temas que se despliegan, aparece la disciplinante necesidad de orientar la mirada hacia la parte positiva de lo vivido, de lo esperable, de lo por venir. No obstante, este "deber ser" de la mirada positiva se ve constantemente negado en su potencialidad, en sus posibilidades concretas, así como en la eventualidad de formulación de propuestas ilusionantes. Tras este tipo de afirmaciones subyace el mandato social del "ser positivo", que remite también a la resignación y al afrontar con entereza las dificultades, con fuertes reminiscencias religiosas (incluida la retórica de los discursos del "salir adelante"...), como parte del discurso mediático que ubica los orígenes de la crisis en el campo de los "estados de ánimo de los mercados", o de los inversores o de las agencias de calificación y, en ello, la necesidad de ofrecer una imagen positiva y mostrarse mirando lo positivo. Además, esa mirada positiva anclada en lo más profundo de la cultura occidental (y que cristaliza entre otras muchas producciones culturales en dichos del tipo: "al mal tiempo buena cara" o "no hay mal que por bien no venga"), tiene, a nivel macrosocial, la potencialidad de ahuyentar el conflicto que fomenta el malestar social. Se despliega la potencialidad de la imagen del bienestar y del fracaso que acompaña al desánimo y al planteamiento de los problemas. De esta manera y trasladándolo al terreno de lo individual, los sujetos han de parecer estar bien, como parte de una especie de terapia de recuperación, han de ser positivos en aras de contribuir en ese estado de ánimo colectivo que parece constituir uno de los elementos germinales de los problemas. Asimismo, en una pirueta doblemente compleja se llega, incluso, a justificar que no tiene sentido la queja y que ésta sería en sí misma adaptativa y reproductora ${ }^{48}$.

Esta autocensura se ve potenciada por un rasgo cultural fuertemente entroncado en la cultura política española. Es el del orgullo, el no mostrar la debilidad y la impotencia, y el sentimiento de vergüenza generado por la necesidad de pedir ayuda. La situación de privación no se evidencia públicamente (sólo en el sector de los muy próximos) ya que es fuertemente estigmatizadora y afecta a la autoestima. En general, para la mayor parte de los sujetos, el pedir ayuda a las instituciones (más allá de las prestaciones a las que se tiene derecho y que están normalizadas) implicaría poner en riesgo su identidad social normalizada (esto es, aparentar estar en la media, ser una familia "normal"). Todos estos elementos potencian un enmascaramiento de las situaciones de pobreza que, en muchas ocasiones, consiguen pasar desapercibidas en el entorno social. Este espacio para el ocultamiento hace que también se resientan las relaciones sociales, dado que se renuncia, por obligación, al ocio relacional que posibilita una parte importante de los espacios de integración

48 "Porque si te sigues quejando: porque la queja también forma parte del sistema ¿sabes? Y salir a la calle a quejarte, eso ya lo saben, y saben que va a existir siempre, siempre porque es dentro de las dos caras de la moneda" (GD1). 
social. Se buscan escusas para no salir al espacio público, para no quedar y, en definitiva, para no relacionarse, de forma que se evidencie su situación de carencia. Este proceso de ocultamiento que conduce al grave deterioro de las relaciones sociales, vendría a abundar en el tipo de análisis desarrollados por diversos autores considerando las formas contemporáneas de la pobreza, al poner énfasis en la incidencia de los procesos de desafiliación laboral y relacional (Castel, 1999), de aislamiento (Katzman, 2001; Steward et al., 2009), y de expulsión social —como concepto alternativo al de exclusión social que proponen, por ejemplo, Duschatzky y Corea (2002: 18) - . Así, el expulsado es un sujeto inexistente, un desaparecido de los escenarios públicos y del intercambio, perdiendo visibilidad; es según estos autores un 'nuda vida".49.

La combinación de la autocensura en dicha política de las apariencias, junto con el sentimiento de vergüenza - y el orgullo implicado - por el hecho de tener que pedir ayuda - con su consiguiente ocultamiento - provoca que las situaciones de pobreza pasen más desapercibidas de lo que los datos nos muestran en muchas de las fuentes que dimensionan la problemática y que se desarrollen debates como el recientemente mantenido sobre la inconveniencia de mostrar la pobreza española a nivel internacional ${ }^{50}$.

Aquí encontraríamos también la insistente emergencia, en los diferentes grupos y entrevistas realizados, de la necesidad de encontrar los aspectos positivos de la crisis que se hacen concretos en la posibilidad de emergencia de reflexión y prácticas ecológicas, la posibilidad de formarse, de cambiar de vida, de recuperar las relaciones familiares, etc., obviando y tratando de enmascarar u ocultar el conjunto de los efectos demoledores de la misma.

\section{Concluyendo}

Se ha podido comprobar cómo para el segmento social de «los nuevos pobres» analizados en esta investigación (para el caso de la Comunidad de Madrid) se está produciendo un proceso de resquebrajamiento del parapeto mítico ideológico sobre el que se asentó buena parte de la legitimidad del modelo social y económico del capitalismo tardío (heredero de los principales postulados de la modernidad liberal). Se puede observar un debilitamiento severo del mito del progreso que se manifiesta en forma de variantes diversas en los colectivos que conforman el heterogéneo

49 "Un ser al que se le han consumido sus potencias, sus posibilidades" (Duschatzky y Corea, 2002: 19).

${ }^{50}$ Este sentimiento de vergüenza y la percepción del deterioro de la imagen española, así como la inconveniencia de mostrar públicamente el momento del deterioro social es puesto de manifiesto y denunciado en alguno de los grupos desarrollado más recientemente (GT2) que se ha celebrado después de la publicación de las fotos que ponen en evidencia circunstancias de pobreza extrema en España, por The New York Times el día 24-9-2012. 
conglomerado de los «nuevos pobres»: espera acechante a un cambio de ciclo, escapismo individual, supervivencia multimovilizada o acabamiento. Entra en crisis también el ideal meritocrático, el espejismo de la pertenencia a una mitificada clase media, así como la legitimidad del sistema de partidos políticos. Paralelamente, se produce un desplazamiento de la capacidad integradora del consumo en un contexto de enmascaramiento de la situación de pobreza y de un fuerte rechazo a considerarse en dicha situación. Todos estos elementos se reelaboran de forma matizada en los diversos segmentos que componen la «nueva pobreza», al tiempo que se desarrollan nuevas configuraciones narrativas y marcos interpretativos legitimadores del nuevo modelo que se está imponiendo. La fragmentación del colectivo y el potenciamiento de las salidas individuales, la culpabilización, el enmascaramiento de los malestares y la censura moral de la protesta vienen a desarrollarse como elementos configuradores de un proceso de reactualización de las justificaciones y legitimaciones de las manifestaciones del capitalismo global contemporáneo.

Como hemos podido ver en esta somera exposición, una de las características básicas de las vivencias de los grupos de «nuevos pobres» ante las situaciones vividas de pobreza, privación y exclusión de múltiples ámbitos de lo social es la heterogeneidad (y la fragmentación), posiblemente asociada con las prácticas de segmentación de las clases populares que se encuentra entre los ejes principales de las formas modernas de gobierno de la población. La falta de empleo, el sentimiento de inutilidad, la necesidad acuciante de ingresos económicos, el fracaso de los proyectos de vida, la incertidumbre ante el futuro, la indignación por el comportamiento de responsables políticos y económicos, todo ello, lejos de generar una corriente común de análisis y de identificación, se inscribe en un escenario social de múltiples identidades, muchas de ellas enfrentadas entre sí, con escasa capacidad para articular soluciones y alternativas y, sobre todo, con pocas opciones para las vivencias colectivas (espacios limitados que lo son aún más como consecuencia de los procesos de ocultación de las situaciones de pobreza y de los procesos de aislamiento que muchas veces les acompañan).

Por otro lado, se hace necesario profundizar en este tipo de análisis, para abordar esta realidad en toda su complejidad, en concreto la ausencia de una fractura social clara - aún en los peores momentos de desempleo y aumento de la pobreza- que debe ser explicada a la luz de los efectos paralizadores y disciplinantes de la crisis, así como por el mantenimiento, aún en estas esferas de la vida de los sujetos empobrecidos, de las esperanzas por regresar a las situaciones de bonanza del pasado, aún más idealizadas si cabe en la actualidad. En todo caso este análisis queda abierto a posteriores desarrollos que deben tener en cuenta los procesos de consolidación de "nuevas" modalidades de precariedad, así como la disolución de otras en las ya establecidas. Por un lado, cabe contemplar nuevos escenarios en los que las dificultades y limitaciones materiales se producen en grupos con un capital cultural y social considerable, lo que, entre otras cosas, facilitará el acceso a redes sociales, pero también producirá unos discursos y esquemas retóricos particulares acerca de la desigualdad, la pobreza y las soluciones posibles, que se distanciarán de otros marcos interpretativos. Por otra parte, es este adjetivo - "nuevo"- el que tiene que 
ser examinado a la hora de caracterizar modalidades de vivencia de la pobreza, tanto por los elementos y condicionantes comunes con otras situaciones, como por su posible continuidad y fijación en el tiempo.

En todo caso, nos encontramos ante una situación en pleno proceso de transformación, donde se produce una reconfiguración de las categorías de poblaciones en situaciones de precariedad o en sus distintas fases; ahí entran en juego factores ya conocidos junto con otros novedosos. Este proceso, en el que se desmontan buena parte de los mitos fundadores de la modernidad, se modula y se declina de muy diversas formas en los distintos espacios y niveles sociales. Para posteriores análisis deberán contemplarse también los efectos que sobre estos procesos están teniendo las políticas públicas —o su ausencia-, así como todos los operativos persuasivos $\mathrm{y}$ retóricos que caracterizan a los distintos grupos.

Se ha abordado, así, una propuesta de un panorama de marcos interpretativos o espacio de actitudes y posiciones un tanto heterogéneo y hasta conflictivo, en el que en medio de un contexto de crisis de legitimación, se reactualizan (y re-significan) los referentes y mitos del consumo, de la responsabilidad individual y del autocontrol del malestar y la protesta.

Se ha tratado de ver cómo, en esta gran fragmentación de las clases populares empobrecidas, se traducen y reproducen discursos que muchas veces justifican el statu quo. Al mismo tiempo, se abren oportunidades de impugnación de dicho escenario, de reactualización mítica a través de propuestas (por el momento minoritarias y escasamente articuladas en este colectivo), de reclamaciones colectivistas y participativas concebidas como forma plausible de frenar un constante proceso de sangrado de derechos y posibilidades, al tiempo que una aspiración hacia una mejora colectiva de las condiciones de vida.

\section{Anexo: ficha técnica de la investigación}

El presente artículo cuenta como base empírica aquella derivada del proyecto subvencionado por la Comunidad de Madrid y la Universidad Complutense de Madrid (convocatoria Dic-2010) con número de referencia CCG10-UC/HUM-4984 y que llevó por título "Miradas sobre la pobreza: representaciones sociales del sector de nuevos pobres de la Comunidad de Madrid en un contexto de crisis económica"

La investigación se basó en el desarrollo de 6 grupos de discusión, 2 grupos triangulares y 8 entrevistas abiertas, en las que participaron un total de setenta personas en situación de «nueva pobreza». El trabajo de campo fue desarrollado en dos fases, una primera entre Mayo y Junio de 2011 en la que se celebraron los grupos de discusión y una segunda entre Junio y Octubre de 2012 en la que se realizaron los grupos triangulares y las entrevistas abiertas. La contactación de los asistentes a los grupos y de las personas entrevistadas fue realizada por la cooperativa Hybris, quienes desarrollaron dicho proceso a través de un gran despliegue de contactos y encuentros en las propias oficinas del INEM, en la puerta de los centros 
escolares, en asociaciones, en espacios de búsqueda de empleo como Infojob, así como a través de la movilización de redes personales de carácter indirecto. Previa a su inserción en los grupos o a la realización de las entrevistas de investigación, se realizaron breves entrevistas telefónicas para comprobar la adecuación a los perfiles demandados. Tras un periodo de consulta y debate en el seno del equipo de investigación de cada uno de los perfiles se seleccionaron los setenta sujetos que constituyen la base del material empírico.

Los criterios que, fundamentalmente, se han tenido en cuenta para organizar el trabajo de campo han sido especialmente la situación laboral (trabajador pobre subempleo- o en paro, de todos los miembros del hogar), el tipo de ocupación (y su relación con los niveles educativos) y la trayectoria laboral, así como la edad, la situación familiar y la condición de autóctono o inmigrante. Otros criterios adicionales que se han tratado de cubrir introduciendo un cierto grado de heterogeneidad en los grupos han sido la situación en relación con la vivienda, la edad de los hijos (cuando los había), la procedencia de los ingresos familiares (subsidios, rentas de inserción, pensiones, ayudas familiares, pensiones alimenticias,) y el género.

La configuración concreta de los grupos y entrevistas fue la siguiente:

\section{Grupos de discusión}

Grupo 1. (GD1) Jóvenes (22-30 años) clase media baja y baja con estudios medios. Trabajos previos precarios, pero con cierta cualificación. La mayor parte aunque no todos - han regresado al hogar paterno, caracterizado también por los escasos recursos económicos.

Grupo 2. (GD2) Varones de clase obrera (35-46 años) (obreros de oficio, fundamentalmente del sector de la construcción) sin cualificación, en posiciones previas de estabilidad o de "precaria estabilidad". En hogares con hijos a cargo. Diversas situaciones en relación con la vivienda.

Grupo 3. (GD3) Adultos (35-50 años) de clase media baja (delineante, comercial, auxiliar enfermería...), con intenso proceso de movilidad descendente. Estudios secundarios o Formación Profesional. Partían de una situación laboral relativamente estable. Con responsabilidades familiares. Diversas situaciones en relación con la vivienda.

Grupo 4. (GD4) Inmigrantes con larga permanencia en España y cualificación media y alta. Nacionalidad rumana. Edades intermedias y diversas situaciones familiares. La mayoría residen en pisos compartidos.

Grupo 5. (GD5) Mujeres en familias monoparentales. Edades intermedias (30-43 años). Diversas edades de los hijos. Variación de las situaciones laborales previas a la separación (amas de casa y trabajadoras). Situaciones variables en relación con la vivienda.

Grupo 6. (GD6) Jóvenes (20-30 años) que habían iniciado su proceso de emancipación, de clase obrera y con muy bajas cualificaciones. En trabajos previos muy precarios. Muchos han regresado al hogar paterno - también con muy bajos recursos-. Procedentes de medios de extracción social baja.

Grupos triangulares 
Grupo triangular 1 (GT1) "Jóvenes-maduros" (35-43 años) con cualificaciones altas y trabajos previos precarios de cualificación alta. Sin cargas familiares. Con participación en asociaciones o grupos de carácter socio-político.

Grupo triangular 2 (GT2) Clase media funcional y profesionales en paro, edades intermedias (37-40 años) con larga y relativamente estable trayectoria de trabajo profesional por cuenta ajena. Procedentes de medios sociales acomodados dos de ellos y de clase media baja el tercero. Con hipoteca - en dos de los casos- y piso cedido - en uno de ellos-.

\section{Entrevistas}

E1- Mujer trabajadora pobre, (44 años), trabaja por horas en comedor escolar. Con hijos y marido en paro. Estudios medios FP1. Reciben ayuda de los padres.

E2- Varón inmigrante marroquí (36 años), casado y con tres hijos. Lleva quince años en Madrid, tiene tarjeta de residencia y ha tenido una multiplicidad de empleos precarios. Actualmente desplazado hacia la recogida de plástico y cartón. Ha vivido en diferentes pisos de alquiler con gran movilidad geográfica. Actualmente vive en infravivienda.

E3- Mujer inmigrante latina (33 años) en paro. Procedente de Bolivia. Lleva siete años en Madrid y tiene permiso de trabajo. Ha trabajado en el servicio doméstico dada de alta en la seguridad social. Tiene estudios de nivel medio. Vive en habitación en piso compartido. Sin hijos.

E4- Varón trabajador manual (53 años) en paro con prestaciones por desempleo agotadas. Estudios secundarios. Casado y con dos hijos mayores. Mujer ama de casa. Ha trabajado de obrero de la construcción con una cierta cualificación. Ocasionalmente como encargado de obra y como autónomo. Actualmente hace alguna "chapucilla" y trabaja en una pequeña huerta de su propiedad en el pueblo. Viven entre Madrid y el pueblo. Están pagando por el aval de la casa hipotecada de un hermano de la mujer. Reciben ayuda de los padres de la mujer.

E5- Varón trabajador de cuello blanco en paro (58 años), con las prestaciones por desempleo agotadas. Tiene estudios de Bachillerato y cursos de formación ocupacional. Está casado y con tres hijos (ya independizados) que les ayudan económicamente de forma puntual. Mujer en el paro cobrando la Renta Activa de Inserción. Trabajó probando coches y como comercial autónomo en una agencia inmobiliaria. Fue desahuciado de su piso en propiedad y ahora vive en un piso en alquiler del que también están a punto de desahuciarle.

E6- Trabajador pobre varón (30 años) trabajos puntuales muy precarizados. Actualmente trabaja como mozo de almacén en una fábrica textil de manera intermitente, sólo cuando le necesitan. Ha trabajado en la construcción, montando pladur, en un almacén de puertas y de camionero. No ha terminado la enseñanza obligatoria. Se independizó con su pareja pero ha regresado a hogar materno.

E7- Mujer trabajadora pobre (28 años), trabajo temporal con un sueldo muy bajo, con gran cantidad de deudas acumuladas, trabaja como operaria en fábrica de pulseras y puntualmente en la venta ambulante de bisutería o como dispensadora de 
entradas en un centro de deporte. Vive en un piso de alquiler con su pareja (sin hijos) que está en paro desde hace ocho meses y sin prestaciones.

E8- Joven con estudios universitarios con trayectoria de inserción precaria en el mercado de trabajo (de alta cualificación) (32 años). Ha estudiado Ingeniería industrial. Ha trabajado como becario y en prácticas durante seis años (incluso en el extranjero y también en la Universidad). Ha tenido un contrato de corta duración ( $\sin$ generar derecho a prestación). Vive con su madre y hermana -con minusvalíaen un piso de alquiler. Su madre está actualmente en el paro aunque ha trabajado toda su vida como camarera y en la limpieza. Actualmente prepara oposiciones.

\section{Bibliografía}

Alonso, L.E., C. Fernández y R. Ibáñez (2011). "Del consumismo a la culpabilidad: en torno a los efectos disciplinarios de la crisis económica", en Política y Sociedad, vol. 8. n 2, pp. 353-379.

Aragón, J., J. y col. (2012). Trabajadores pobres y empobrecimiento en España. Madrid: Fundación $1^{\circ}$ de Mayo. Colección estudios n 56.

Augé, M. (2008). Los no lugares. Espacios del anonimato. Una antropología de la sobremodernidad. Barcelona: Gedisa.

Belzunegui, A. (2012) (coord.). Socialización de la pobreza en España. Género, edad y trabajo en los riesgos ante la pobreza. Barcelona: Icaria.

Belzunegui, A. y I. Pastor (2012). "Radiografía de la pobreza en España". En Belzunegui, A. (2012) (coord.) Socialización de la pobreza en España. Género, edad y trabajo en los riesgos ante la pobreza. (pp. 35-66) Barcelona: Icaria.

Bourdieu P. (1999) (dir.). La miseria del mundo. Akal, Madrid.

Castel, R. (1999). La metamorfosis de la cuestión social. Una crónica del salariado. Barcelona: Paidós.

Castillo Gallardo, M. (2011). "El lugar de los trabajadores. Pobreza e identidad política en Chile contemporáneo". En J. Arzate, A. Gutiérrez y J. Huamán (coord.) Reproducción de la pobreza en América Latina. Relaciones sociales, poder y estructuras económicas. (pp. 83-112). Buenos Aires: CLACSO.

Colectivo Ioé (2012). "Crece la desigualdad en España”. En Barómetro social de España. Edición on line. http://www.fuhem.es/media/ecosocial/File/Analisis/2012/BSE2010Desigualdad.pdf. Consultado: Abril, 2012. 
Conde Gutiérrez del Álamo, F. (2008). Análisis sociológico del sistema de discursos. Madrid: CIS, Colección cuadernos metodológicos, $\mathrm{n}^{\circ} 43$.

Duschaatzky, S. y C. Corea (2002). Chicos en banda. Los caminos de la subjetividad en el declive de las instituciones. Buenos Aires: Paidós.

EAPN (2012). Las cifras de pobreza y exclusión social en España de cara a Europa 2020. Madrid: EAPN.

Equipo de Estudios de Cáritas (2012). De la coyuntura a la estructura. Efectos permanentes de la crisis. Madrid: Cáritas. VII Informe del Observatorio de la realidad social.

Embid, J. (Coor.) (2013). Primer informe sobre la desigualdad en España. Madrid: Fundación Alternativas.

FOESSA (2013). Desigualdad y derechos sociales. Madrid: Fundación FOESSA.

Goffman, E. (2006). Frame Analysis. Los marcos de la experiencia. Madrid: CIS.

Green, B. L. y A. Rodgers (2001). "Determinants of social support among low income mothers: A longitudinal analysis". American Journal of Psychology, vol $29 \mathrm{n}^{\circ} 3,419-441$.

Gutiérrez, A.B. (2004a). Pobre, como siempre... Estrategias de reproducción social en la pobreza: un estudio de caso. Córdoba: Ferreyra editor.

Gutiérrez, A.B. (2004b). "La teoría de Bourdieu en la explicación y comprensión del fenómeno de la pobreza urbana", en L.E.Alonso, E. Martín Criado y J.L. Moreno Pestaña (eds.) Pierre Bourdieu: las herramientas del sociólogo. (pp. 255-282). Madrid: Fundamentos.

Habermas, J. (1995). Problemas de legitimación en el capitalismo tardío. Buenos Aires: Amorrortu.

Hatfield, M. (2004). "Vulnerability to persistent low income". Horizons: Policy Research Initiative, vol. 7, $\mathrm{n}^{\circ}$ 2, 19-33.

INE (2012). Encuesta de Condiciones de Vida. (ECV) Consultado el 20-11-2012 http://www.ine.es/jaxi/menu.do?type $=$ pcaxis $\&$ path $=\% 2 \mathrm{Ft} 25 \% 2 \mathrm{Fp} 453 \&$ file $=$ ineb ase $\& \mathrm{~L}=0$

INE (2012). Encuesta de población activa (EPA). Consultado el 20-11-2012 http://www.ine.es/jaxi/menu.do?type $=$ pcaxis\&path $=/ t 22 / e 308 \_$mmu\&file $=$inebase $\& L=0$ 
Intermón-Oxfam (2012). Crisis, desigualdad y Pobreza. Informe Intermón Oxfam, $\mathrm{n}^{\circ}$ 32, Dic. 2012.

Kaen, C (2012). "Discurso de la pobreza en el campo académico y estigmas construidos". En Margen, nº 65, Julio, pp.1-16.

Katzman, R. (2001). "Seducidos y abandonados: el aislamiento social de los pobres urbanos". Revista de la CEPAL, $\mathrm{n}^{\circ}$ 75. Diciembre 2001, pp.171-189.

Lakoff, G. (2007). No pienses en un elefante: lenguaje y debate político. Madrid: Editorial Complutense.

Laparra, M. y B. Pérez Eransus (2012). Crisis y fractura social en Europa. Causas y efectos en España. Barcelona: La Caixa. Colección Estudios Sociales, $\mathrm{n}^{\circ} 35$.

Laparra, M. Y Pérez Eransus (2010). El primer impacto de la crisis en la cohesión social en España. Madrid: Fundación FOESSA. Colección de estudios nº 32.

Lenoir, R (1984). Les exclus: un français sur dix. Paris: Editions du Seuil.

Lewis, O. (1961). Antropología de la pobreza. Cinco familias . México: FCE.

Lewis, O. (1964). Los hijos de Sánchez. Autobiografía de una familia mexicana. Mexico: Mortiz.

López Jiménez, J.J y V. Renes (2011). "Los efectos de la crisis en los hogares: nivel de integración y exclusión social". Papeles de relaciones eco-sociales y cambio social no 113, pp. 189-199.

Merklen, D. (2005). Pobres ciudadanos: Las clases populares en la era democrática (Argentina, 1983-2003) Buenos Aires: Editorial Gorla.

Minujin, A y E. Anguita (2004). La clase media seducida y abandonada. Buenos Aires: Edhasa.

Murad, N. (2002). "Guilty Victims: Social Exclusion in Contemporary France", en P. Chamberlayne, M. Rustin y T. Wenraf, (eds.). Biography and Social Exclusion in Europe. Bristol: Policy Press (pp. 41-60).

Narayan, D. (2000). La voz de los pobres. ¿Hay alguien que nos escuche? Madrid: Ediciones Mundi-Prensa.

Nayaran, D. y Petesch, P. (2002a). La voz de los pobres. Desde muchas tierras. Madrid: Ediciones Mundi-Prensa. 
Narayan, D., Chambers, R., Shah, M.K \& Petesch, P (2002b). La voz de los pobres: clamando por el cambio Madrid: Ediciones Mundi-Prensa.

Navarro, V. (2006). El subdesarrollo social de España. Causas y consecuencias. Barcelona: Anagrama

Navarro, V. (dir.) (2012). El impacto de la crisis en las familias y en la infancia. Barcelona: Ariel

Paugam S. (2007). Las formas elementales de la pobreza. Alianza: Madrid.

Pérez Eransus, B. (2013). "El impacto de las políticas de ajuste en la cohesión social en España", en FOESSA. Desigualdad y derechos sociales. (pp. 38-48). Madrid: Fundación FOESSA.

Ramos Mejía, M (2011). "Las clases medias y los pobres en la Argentina del modelo neoliberal". BuenasTareas.com. Recuperado 10, 2011, de http://www.buenastareas.com/ensayos/Clase-Media/2988124.html

Rodríguez Cabrero, G. (2004). El Estado del Bienestar en España: debates, desarrollo y retos. Madrid: Fundamentos.

Salido Cortés, O. (2012). Los ciudadanos españoles ante la crisis. Madrid: Fundación Alternativas.

Sarasa, S. y L. Moreno (comp.) (1995). El Estado del Bienestar en Europa del Sur. Madrid: IESA-CSIC.

Stewart, M.J., E. Makwarimba, L. Reutter, G. Veenstra, D. Raphael \& R. Love (2009). "Poverty, Sense of Belonging and Experiences of Social Isolation". Journal of Poverty, 13:2, 173-195.

Therborn, G. (1987). La ideología del poder o el poder de la ideología. Madrid: Siglo XXI

Wacquant L. (2007). Los condenados de la ciudad. Gueto, periferias y Estado. Buenos Aires: Siglo XXI.

Wacquant, L. (2012). Merodeando las calles. Trampas de la etnografía urbana. Barcelona: Gedisa.

Wetherell, M. y J. Potter (1996). "El análisis del discurso y la identificación de los repertorios interpretativos". En A. Gordo y J.L. Linaza (coord.). Psicologías, discursos y poder. Madrid: Visor. 